\title{
Advanced Nanoporous Anodic Alumina-Based Optical Sensors for Biomedical Applications
}

\author{
Silu Feng * and Weiwei Ji \\ College of Physics and Electronic Science, Hubei Normal University, Huangshi, China
}

OPEN ACCESS

Edited by:

Deqiang Wang,

Chongqing Institute of Green and Intelligent Technology (CAS),

China

Reviewed by:

Tushar Kumeria,

University of New South Wales, Australia

Mohammad Kouhi, Islamic Azad University of Tabriz, Iran Linlong Tang,

Chongqing Institute of Green and Intelligent Technology (CAS),

China

*Correspondence:

Silu Feng

siuf1230@163.com

Specialty section: This article was submitted to Biomedical Nanotechnology,

a section of the journal Frontiers in Nanotechnology

Received: 09 March 2021 Accepted: 26 April 2021

Published: 28 May 2021

Citation:

Feng S and Ji W (2021) Advanced Nanoporous Anodic Alumina-Based Optical Sensors for

Biomedical Applications.

Front. Nanotechnol. 3:678275. doi: 10.3389/fnano.2021.678275
Close-packed hexagonal array nanopores are widely used both in research and industry. A self-ordered nanoporous structure makes anodic aluminum oxide (AAO) one of the most popular nanomaterials. This paper describes the main formation mechanisms for $A A O$, the AAO fabrication process, and optical sensor applications. The paper is focused on four types of AAO-based optical biosensor technology: surface-Enhanced Raman Scattering (SERS), surface Plasmon Resonance (SPR), reflectometric Interference Spectroscopy (RIfS), and photoluminescence Spectroscopy (PL). AAO-based optical biosensors feature very good selectivity, specificity, and reusability.

Keywords: nanoporous, anodic aluminum oxide (AAO), self-ordering anodization, Optical biosensor, Detection

\section{INTRODUCTION}

$\mathrm{Al}$, the third most abundant element and the most abundant metal, makes up about $8 \%$ of the Earth's crust. Taking advantage of its reactivity with naturally occurring oxygen in the atmosphere, Sir Humphrey Davy, physicist Hans Christian Ersted, and Karl Bayer were able to refine and improve the manufacturing of alumina from bauxite ore (Poinern et al., 2011). Today, Alumina $\left(\mathrm{Al}_{2} \mathrm{O}_{3}\right)$ is widely used in many applications and has become the most widely produced non-ferrous metal (United States Geological Survey, 2011).

In the mid 1920s, anodization using $\mathrm{Al}$ in chromic acid was developed (HM Wire International Inc. 2010). The oxide structure consists of two distinct layers. The first forms a non-porous barrier layer, while in the second a thicker, porous oxide structure, an anodic aluminum oxide layer, is formed. The porous nature of anodic alumina films was discovered by S. Setch and A. Miyatain in 1932 (Setoh and Miyata, 1932) and further characterized by F. Keller's group in 1953 (Keller et al., 1953) and J. P. O'Sullivan's group in 1970 (O'sullivan and Wood, 1970). In 1974, the Boeing Company used chromic acid, sulfuric acid, or phosphoric acid in producing anodic aluminum oxide membranes (Smith, 1974). Because of AAO's uniform nanostructure, it began to attract interest during the late 1980s in the area of nanotechnology. In the mid-1990s, AAO was applied for bottomup templated nanofabrication (Masuda and Fukuda, 1995; Masuda et al., 2001). Oxide layers generated during anodization can also be produced on materials such as niobium ( $\mathrm{Nb}$ ) ( $\mathrm{Lu}$ et al., 2005; Sieber et al., 2005; Stróz et al., 2019; Altomare et al., 2020), silicon (Si) (Xia et al., 2000; Rodriguez et al., 2005; Formentín et al., 2015; Elia et al., 2016), tantalum (Ta) (Sieber et al., 2006; Barton et al., 2009; Wei et al., 2009; Yu et al., 2013; Wang et al., 2015; Fialho et al., 2020), titanium (Ti) (Kim et al., 2014; Zheng et al., 2014; Nguyen et al., 2017; Anitha et al., 2018), etc.

Since 2000, AAO has become more popular, both in research and in industrial fields such as biosensing, bio-detection, drug delivery, etc (Pan et al., 2003; Vlassiouk et al., 2004; Takmakov et al., 2006; Flamme et al., 2007; Yang et al., 2007; Alvarez et al., 2009a; Wang et al., 2001). AAO-based optical biosensors are widely used in broad range of fields. The four optical methods most commonly 

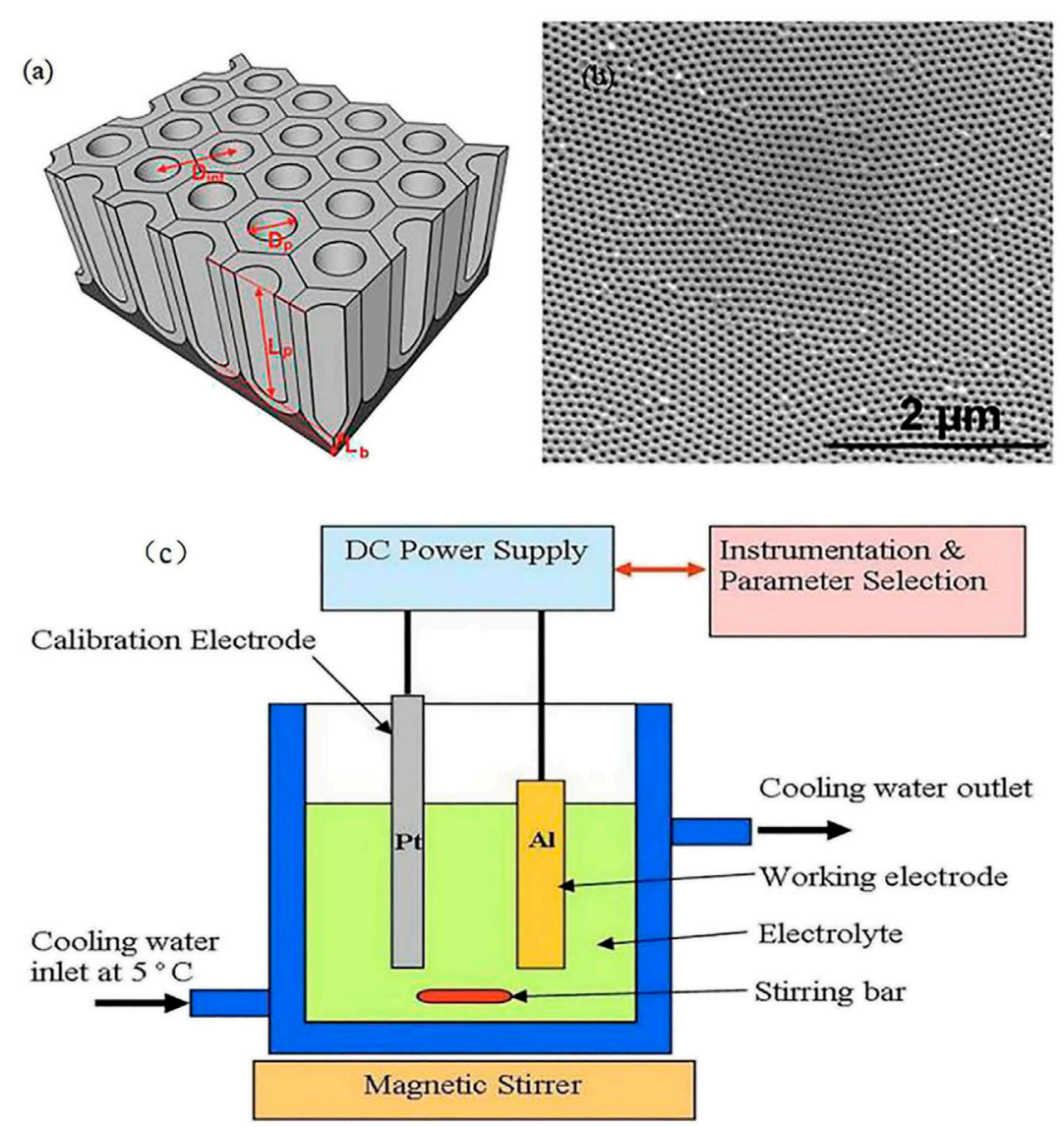

FIGURE 1 | (A) Schematic describing the structural characteristics of AAO); (B) Top SEM image of AAO (Kumeria et al., 2014); (c) Experimental equipment used to produce anodized aluminum oxide (Poinern et al., 2011).

used in AAO are: surface-Enhanced Raman Scattering (SERS), surface Plasmon Resonance (SPR), reflectometric Interference Spectroscopy (RIfS), and photoluminescence Spectroscopy (PL). In this review, we will first introduce the structure and fabrication process of $\mathrm{AAO}$, then illustrate several main formation models for the origin of pore nuclei and the exact mechanism of pore nucleation, and finally discuss AAO-based optical biosensor applications.

\section{FABRICATION, STRUCTURE AND FORMATION MECHANISMS OF AAO}

\section{Fabrication of AAO}

During the mid-1990s, Masuda, H's group, fabricated AAO using $0.3 \mathrm{M}$ chromic acid at $0^{\circ} \mathrm{C}$ and with $40 \mathrm{~V}$ applied voltage for $160 \mathrm{~h}$ anodization time, resulting in the type of highly ordered AAO shown in Figure 1A (Masuda and Fukuda, 1995). In further research, Masuda and Fukuda developed the two-step anodization process (Masuda and Fukuda, 1995). In the first step, thick aluminum plates are placed in acidic solution for $2-24 \mathrm{~h}$ to form a nonuniform nanoporous structure, enabling propagation and self-organized growth of cylindrical nanopores from top to bottom during the course of the second anodization step. Samples are rinsed in DI water and dipped in an etching mixture of $\mathrm{H}_{3} \mathrm{PO}_{4}$ and chromic acid $\left(\mathrm{H}_{2} \mathrm{CrO}_{4}\right)$, removing the oxide layer formed during the first anodization and leaving weak points at the $\mathrm{Al}$ plated surface for the second anodization carried out using similar apparatus. Table 1 (Poinern et al., 2011) shows the major acid components used to produce AAO.

This fabrication process can be performed using commonly available laboratory equipment (Figure 1C; Poinern et al., 2011). A dual-wall container is first prepared with acid and cooling water used in the anodization process, with a cooling system connected to an RF machine for cooling water to a temperature of $2^{\circ} \mathrm{C}-8^{\circ} \mathrm{C}$, after which an acid solution functioning as an electrolyte is poured into the container. Most researchers tend to use oxalic, phosphoric, and sulfuric acid, etc. (Santos et al., 2013a). Two working electrodes, aluminum as the anode and platinum as the cathode, are needed during the anodization process. A rectifier is used to apply a DC voltage across the two electrodes, and the $\mathrm{Al}$ is gradually anodized to form a nanoporous structure. As shown in Figures 1A,C stirring bar and magnetic stirrer at the tank bottom are used to ensure uniformity of the acid concentration and assure a smooth and stable anodization process. 
TABLE 1 | Major acid components of typical electrolyte types used to produce porous oxide layer on an aluminum substrate (Poinern et al., 2011).

\begin{tabular}{|c|c|c|c|}
\hline $\begin{array}{l}\text { Main acid used in } \\
\text { electrolyte }\end{array}$ & Molecular formula & Concentration (M) & Pore size Range (nm) \\
\hline Acetic & $\mathrm{CH}_{3} \mathrm{CO}_{2} \mathrm{H}$ & 1 & Not specified \\
\hline Citric & $\mathrm{HO}_{2} \mathrm{CCH}_{2}(\mathrm{OH})\left(\mathrm{CO}_{2} \mathrm{H}\right) \mathrm{CH}_{2} \mathrm{CO}_{2} \mathrm{H}$ & 0.1 to 2 & 90 to 250 \\
\hline Chromic & $\mathrm{H}_{2} \mathrm{CrO}_{4}$ & 0.3 .0 .44 & 17 to 100 \\
\hline Glycolic & $\mathrm{CH}_{2}(\mathrm{OH}) \mathrm{CO}_{2} \mathrm{H}$ & 1.3 & 35 \\
\hline Malic & $\mathrm{HO}_{2} \mathrm{CH}_{2} \mathrm{CH}(\mathrm{OH}) \mathrm{CO}_{2} \mathrm{H}$ & 0.15 to 0.3 & Not specified \\
\hline Malonic & $\mathrm{CH}_{2}\left(\mathrm{CO}_{2} \mathrm{H}\right)_{2}$ & 0.1 to 5 & Not specified \\
\hline Oxalic & $\mathrm{C}_{2} \mathrm{H}_{2} \mathrm{O}_{4}$ & 0.2 to 0.5 & 20 to 80 \\
\hline Phosphoric & $\mathrm{H}_{3} \mathrm{PO}_{4}$ & 0.04 to 1.1 & 30 to 235 \\
\hline Sulfuric & $\mathrm{H}_{2} \mathrm{SO}_{4}$ & 0.18 to 2.5 & 12 to 100 \\
\hline Tartaric & $\mathrm{HO}_{2} \mathrm{CCH}(\mathrm{OH}) \mathrm{CH}(\mathrm{OH}) \mathrm{CO}_{2} \mathrm{H}$ & 0.1 to 3 & Not specified \\
\hline
\end{tabular}

\begin{tabular}{|c|c|c|c|c|}
\hline Acid & Concentration (M) & Voltage (volts) & Pore size (nm) & Time (hours) \\
\hline \multirow[t]{11}{*}{ Oxalic } & 0.25 & 60 & 75 & 8.8 variable \\
\hline & 0.3 & 40 & Not specified & 8, variable \\
\hline & 0.3 & 40 & 80 & $10.5 \min$ \\
\hline & 0.3 & 40 & 50 & 3.8 \\
\hline & 0.3 & 60 & 80 & 40 min,2 variable \\
\hline & 0.3 & 40 & $40-50$ & 8.10 \\
\hline & 0.3 & 40.50 & 20.35 & 8.10 \\
\hline & 0.3 & 30 & 40 & 8.10 \\
\hline & 0.4 & 40 & 50 & $12,4,8,12$ and 16 \\
\hline & 0.5 & 50 & 80 & \\
\hline & 0.3 & 40 & 22 & \\
\hline \multirow[t]{4}{*}{ Phosphoric } & Not specified & 195 & 200 & Variable \\
\hline & 0.4 & 5 to 40 & 20 to 75 & 1 step/variable \\
\hline & 0.4 & 80 & 80 & 1 step \\
\hline & 0.42 & 87 to 117 & 64 to 79 & 1 step/variable \\
\hline \multirow[t]{4}{*}{ Sulfuric } & 0.5 & 18 & 70 & 4, variable \\
\hline & 2.4 & 15 to 25 & 13 to 27 & 2 step/variable \\
\hline & Not specified & $12,25,40$ & $25.50,100$ & Not specified \\
\hline & 0.3 & 25 & 20 & $12,4,8,12$ and 16 \\
\hline
\end{tabular}

There are other methods to obtain ordered alumina porous membranes. One uses a $\mathrm{SiC}$ single-crystal wafer as a mold with a hexagonally ordered array of convexes to generate an array of concavities on the surface of Al (Masuda et al., 1997), followed by immersion in an oxalic acid solution under constantvoltage conditions with $\mathrm{Al}$ anodization. The result confirms that the predetermined pattern formed by mechanical deformation can act as asset of initiation points and guide the growth of channels in the oxide film. While this method can fabricate a long-range-ordered channel array with a high aspect ratio, it involves significantly high preparation costs and a complex process.

Self-ordered AAO can be described as close-packed arrays of hexagonally arranged cells. Several parameters define the AAO structure (Anglin et al., 2008). First, pore density describes how many pores exist per $\mathrm{cm}^{2}$, with porosity defined as the percentage occupancy of pores over an AAO surface, normally ranging from $5-50 \%$. Pore diameter $\left(d_{p}\right)$ usually lies between 10 and $400 \mathrm{~nm}$. Interpore distance $\left(d_{\text {int }}\right)$ is the distance between the middle points of two neighboring nanopore walls $(50-600 \mathrm{~nm})$, and pore length $\left(L_{p}\right)$ is the thickness of the AAO layer $\left(\tau_{o b l}\right)$, typically ranging between 10 and $150 \mathrm{~nm}$. Figure 1B shows a typical AAO structure (top and cross-section).

All AAO parameters can be precisely adjusted by controlling the anodization process (Losic and Losic, 2009; Santos et al., 2011). A variety of acids can be used in the anodization process to produce different nanopore diameters, and some experiments have used a combination of acids for this purpose. Table 1 shows the major acid components used to produce AAO. There are four types of porous anodization processes: mild anodization (MA), hard anodization (HA), pulse anodization (PA), and cyclic anodization (CA), and most experiments have used the MA process at moderate voltages and temperatures. Various studies have described use of aqueous solutions of sulfuric acid $\left(\mathrm{H}_{2} \mathrm{SO}_{4}\right)$, oxalic acid $\left(\mathrm{H}_{2} \mathrm{C}_{2} \mathrm{O}_{4}\right)$ and phosphoric acid $\left(\mathrm{H}_{3} \mathrm{PO}_{4}\right)$ as electrolytes for an anodization process at voltages of 25,40 , and $195 \mathrm{~V}$, respectively (Alkire et al., 2008; Lee et al., 2008; Losic et al., 2009; Santos et al., 2011; Lee and Park, 2014). Table 2 shows some of the voltage settings and times used in the fabrication of a nano-porous oxide layer (Poinern et al., 2011). In this section, while we present a AAO fabrication process 
prepared by electrochemical anodization of aluminum, there are many other fabrication methods, as described in another review paper by Rath and Theato (Rath and Theato, 2020).

\section{AAO Formation Mechanisms}

\section{Thermodynamics and Kinetics}

It is well-known that the presence of oxygen is advantageous when aluminum is used to produce alumina, even at room temperature. For an $\mathrm{Al}$-water system, 6 reactions are known to occur:

$$
\begin{aligned}
2 \mathrm{Al}+3 \mathrm{H}_{2} \mathrm{O} & =\mathrm{Al}_{2} \mathrm{O}_{3}+6 \mathrm{H}^{+}+6 \mathrm{e}^{-}, \\
\mathrm{Al}^{3+}+2 \mathrm{H}_{2} \mathrm{O} & =\mathrm{AlO}_{2}^{-}+4 \mathrm{H}^{+}, \\
2 \mathrm{Al}^{3+}+3 \mathrm{H}_{2} \mathrm{O} & =\mathrm{Al}_{2} \mathrm{O}_{3}+6 \mathrm{H}^{+}, \\
\mathrm{Al}_{2} \mathrm{O}_{3}+\mathrm{H}_{2} \mathrm{O} & =2 \mathrm{AlO}_{2}^{-}+2 \mathrm{H}^{+}, \\
\mathrm{Al} & =\mathrm{Al}^{3+} 3 \mathrm{e}^{-}, \\
\mathrm{Al}+2 \mathrm{H}_{2} \mathrm{O} & =\mathrm{AlO}_{2}^{-}+4 \mathrm{H}^{+}+3 \mathrm{e}^{-} .
\end{aligned}
$$

These equations determine the nature of the electrochemical reactions occurring in nature (reactions (Eqs. 1, 5, 6)). If the reaction is chemical in nature, it is determined by the Gibb's free energy (reactions Eqs. 2-4)). Different reaction equations can also occur if different acidic and basic solutions are used during the fabrication process. Reaction (Eq. 1) can be described as $\mathrm{Al}_{2} \mathrm{O}_{3}$ grown thermodynamically in weak acidic and basic solutions, with a barrier layer known to grow under these conditions (Young, 1961; Diggle et al., 1969; Scully, 1983; Despić and Parkhutik., 1989). Reaction (Eq. 6) represents the anodization process that occurs in a strong acid such as perchloric acid through a process called electropolishing, involving $\mathrm{Al}$ dissolving into the solution (Despic and Parkhutik., 1989). If the anodization process uses mildly acidic solutions such as oxalic and sulfuric acids, porous alumina grows as a result of anodization (Young, 1961; Diggle et al., 1969; Scully, 1983; Despić and Parkhutik., 1989), where it is widely believed that a combination of the oxidation reaction (Eq. 1) and the $\mathrm{Al}$ dissolution reaction (Eq. 6) occurs (Diggle et al., 1969).

An anodic oxide grows simultaneously at both interfaces through ionic $\left(\mathrm{Al}^{3+}\right.$ and $\left.\mathrm{O}^{2-}\right)$ transport, and the most important electrolyte-related factor is its capability for maintaining a significant flow of $A l^{3+}$ ions from the metal substrate into the electrolyte. There are two ways to achieve this goal: electrical-field-driven direct expulsion of ions, and dissolution of the forming oxide layer. $A l^{3+}$ ions initially migrate from the metal substrate through the metal/oxide interface to the oxide layer, while $\mathrm{O}^{2-}$ ions from the water pass through the oxide/electrolyte interface into the oxide layer. At this stage, approximately $70 \%$ of the $A l^{3+}$ and the $\mathrm{O}^{2-}$ ions form a barrier layer, while the remaining $A l^{3+}$ ions dissolve into the electrolyte. The barrier layer then is transformed into a semi-spherical oxide layer of constant thickness that forms the pore bottom. Figure $\mathbf{2 A}$ is a schematic diagram of pore formation mechanism in an acidic electrolyte (Poinern et al., 2011).

The chemical reaction equation for $\mathrm{Al}$ anodization is:

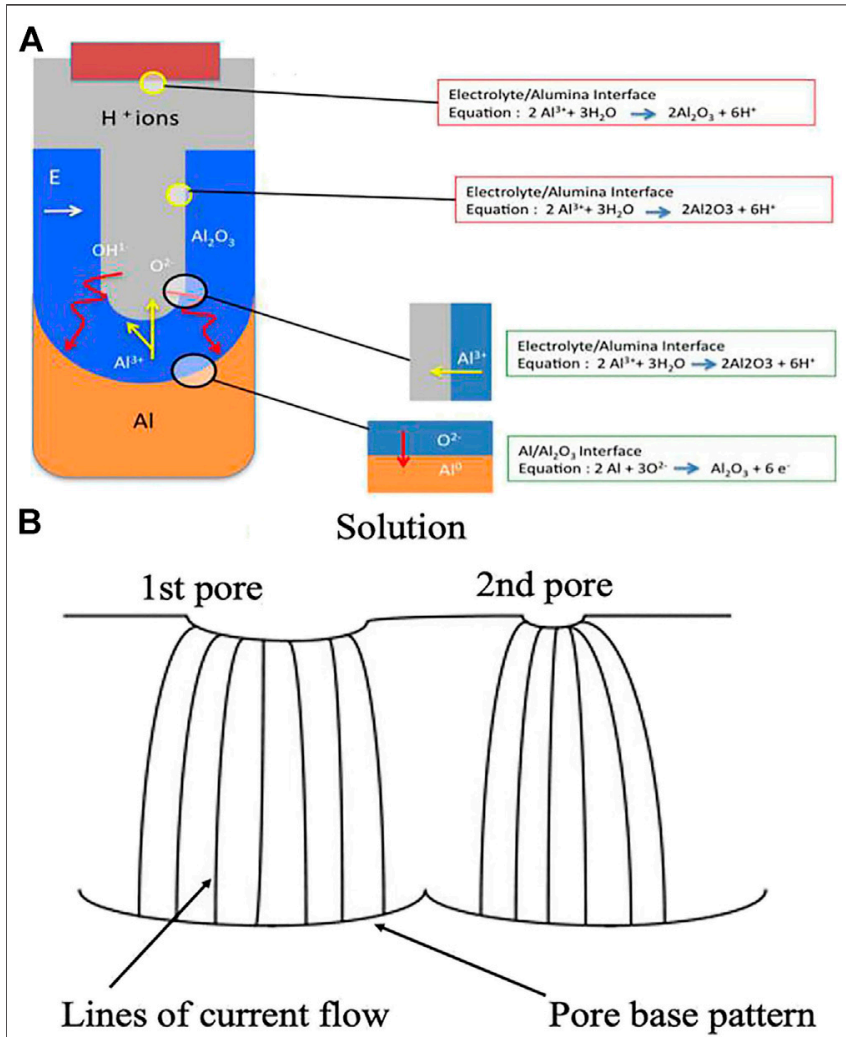

FIGURE 2 | (A) Schematic of ion movement during pore formation; (B) Schematic picture demonstrating the spreading of pore nuclei on the surface of the initial barrier film.

$$
2 \mathrm{Al}+3 \mathrm{H}_{2} \mathrm{O} \rightarrow \mathrm{Al}_{2} \mathrm{O}_{3}+3 \mathrm{H}_{2}\left\{\begin{array}{c}
6 \mathrm{H}^{+}+6 e^{-} \rightarrow 3 \mathrm{H}_{2} \\
2 \mathrm{Al}+3 \mathrm{O}^{2-} \rightarrow \mathrm{Al}_{2} \mathrm{O}_{3}+6 \mathrm{H}^{+} \\
2 \mathrm{Al}^{3+}+3 \mathrm{H}_{2} \mathrm{O} \rightarrow \mathrm{Al}_{2} \mathrm{O}_{3}+6 \mathrm{H}^{+}
\end{array}\right.
$$

The electric field at the base of the hemispherically shaped pores can force both $\mathrm{Al}^{3+}$ migration through the barrier layer and $\mathrm{O}^{2-}$ and $\mathrm{OH}^{-}$migration from the metal/oxide interface into the pore base oxide layer, as shown in Figure 2A, explaining how the electric field can influence the size of the pore diameter. If the electric field is too small, there are not enough $A l^{3+}$ ions to pass through the barrier layer, so there is less nanopore-forming reaction. The film growth rate is determined by each kinetic step and various authors have proposed anodic oxide growth models (Diggle et al., 1969; Lohrengel, 1993; Zhang et al., 1998). The kinetics of $\mathrm{Al}$ anodization can also be described either with a high-field conduction model or the Güntherschultz-Betz (G-B) equation:

$$
j_{i}=j_{0} \exp (\beta E) .
$$

Here, $j_{i}$ is the ionic current density due to the ion species $i, j_{0}$ and $\beta$ are temperature-dependent parameters, and $\mathrm{E}$ is the electric field across the oxide. In general, the nanoporous oxide layer 
consists of a thin nonporous oxide layer continually regenerated at the base of the pore, with the pore wall increasing in height with time as it is being created.

During the fabrication process, both pore size and distance between pores are functions of the acid concentration, the anodic voltage, and the temperature. The nanopore diameter is the key parameter determining AAO's performance, especially AAO used as an optical biosensor (Tinsley-Bown et al., 2000; Kazuhiro et al., 2010; Kumeria and Losic, 2012; Kant et al., 2014). In their initial work, Macias et al., fabricated AAO with three different pore diameters to detect serially dosing protein $\mathrm{A}$, human IgG, and anti-human IgG using RIFS, with results that revealed no significant difference in optical signal shift observed when using nanopore diameters of $32 \pm 4 \mathrm{~nm}$, while the optical signal shift increased when the concentration of protein was increased using larger pore diameters (50 and $73 \mathrm{~nm}$ ) (Macias et al., 2015). Another experiment has also demonstrated that the nanopore diameter should greater than $50 \mathrm{~nm}$ for efficient binding of both the detector and capture antibody (TinsleyBown et al., 2000). When pore diameters are too small, they can hinder protein diffusion inside the structure, and the limit of detection (LOD) for detecting theophylline using larger pore diameter $(50 \mathrm{~nm})$ is much lower than when using $10 \mathrm{~nm}$ AAO (Feng et al., 2018). These results indicate that the limit of detection of the nanopore sensors can be optimized by varying the nanopore size.

\section{Pore-formation Mechanisms}

The origin of pore nuclei and the exact mechanism of pore nucleation are still debated, with several formation models proposed (Hoar and Mott., 1959; Thompson et al., 1978). The first detailed AAO mechanism was investigated by Keller, et al. During the anodization process, high current initially flows through the $\mathrm{Al}$ plates and oxide forms rapidly; after a short time, current decreases to a relatively low steady state during which a "barrier" or "blocking" type of oxide coating is formed. At the same time, solvent action by electrolyte begins to occur, the thickness of the barrier layer is reduced, and the electrolyte temperature rises. The solvent action also forms a single point of oxide because current flow, heating, and solvent action will be localized and the pore enlarges in proportion to the amount of metal consumed, resulting in a hexagonal pore shape. Keller described two types of oxide that can be produced, a barrier layer and a nano-porous oxide layer. Akahori suggests a new assumption for describing the AAO film-growth mechanism; after the barrier layer and point are formed, the temperature at the bottom of the point is higher and the electrolyte would tend to evaporate, causing the aluminum to be dissolute. The $\mathrm{O}^{2+}$ at the bottom would then go through the oxide layer and react with liquid state aluminum, suggesting that the barrier layer is composed of both $\mathrm{Al}_{2} \mathrm{O}_{3}$ and $\mathrm{Al}$.

Hoar and Mott in 1959 first proposed the field-assisted dissolution model (Hoar and Mott, 1959). In that model, once the cell voltage drops, both proton passage into the barrier layer against the field and the dissolution rate of $\mathrm{Al}_{2} \mathrm{O}_{3}$ are greatly enhanced. As shown in Figure 2B, the electric field increases at the pore bottom and the oxide dissolution rate also increases.
Specifically, the $\mathrm{Al}_{2} \mathrm{O}_{3}$ at the oxide/electric interface is spontaneously decomposed to $\mathrm{Al}^{3+}$ and $\mathrm{O}^{2-}$ in contact with acids, and the $\mathrm{O}^{2-}$ ions react with $\mathrm{H}^{+}$to become $\mathrm{OH}^{-}$ions in the acid that are transported to the metal/oxide interface by the high electric field to form new oxide at the metal/oxide interface. At this time, since $A l^{3+}$ goes into the solution, pore depth begins to form, and during porous film formation, the barrier layer becomes slightly thinner. Once the first pore has been formed, a second pore would form at the edge of the first at the point where the heating effect is largest. O'Sullivan and Wood in 1970 present a more detailed description of the electrochemical dissolution reaction (Diggle et al., 1969; O'Sullivan and Wood, 1970; Cherki and Sieika, 1973) explaining why pores grow at all and why their size distribution is quite narrow.

These models show that the formation mechanism of alumina is not very clear except that it includes a dynamic process involving ions, and formation of a self-organized nanopore array has not been thoroughly explained. The main models used to explain this formation mechanism are a volumeexpansion model (Jessensky et al., 1998) and a dielectric breakdown model (Su et al., 2012).

In 1998, Jesenskey's group (Jessensky et al., 1998) proposed a new model, a volume-expansion model, to explain conditions leading to self-organized formation of ordered hexagonal structures in anodic alumina. Once the porous oxide has grown, since the atomic density of aluminum in alumina is lower than in metallic aluminum, mechanical stress will be generated at the metal/oxide interface through alumina formation, and this mechanical stress may cause a force between neighboring pores. Since the oxide is simultaneously formed at the metal/oxide interface, the material can only expand in the vertical direction, so existing pore walls are pushed upward. After the oxide has formed, alumina volume is larger than that of metallic aluminum, so volume expansion during oxide growth causes repulsive forces between neighboring pores during the oxidation process. To minimize the energy of the whole system, nanopores will form into self-organized hexagonal pore arrays. The model also demonstrates that the oxidation rate of aluminum, the volume expansion, the thickness of the alumina strongly depends on the anodizing voltage and which electrolyte is used.

Su's group (Su et al., 2012) in 2012 described another model, the dielectric breakdown model. That study compared the formation mechanism of anodic aluminum oxide to that of anodic titanium oxide and also explained the formation of nanopores and nanotube anodic metal oxides shown in Figure 3. It has been suggested that the degree of localized dielectric breakdown, mainly determined by the dielectric strength and energy band gap of the anodic oxide, the electrolyte used, the anodizing field, and the temperature during anodization, has a significant effect on pore formation. During the anodization process, because of continuous dielectric breakdown, oxygen voids can grow and accumulate at the oxide/ metal interface. If there is a sufficiently high degree of localized dielectric breakdown due to a large anodizing field, high temperature, or low dielectric strength of the resulting oxides, the dominant dielectric breakdown may occur at the oxide/metal 

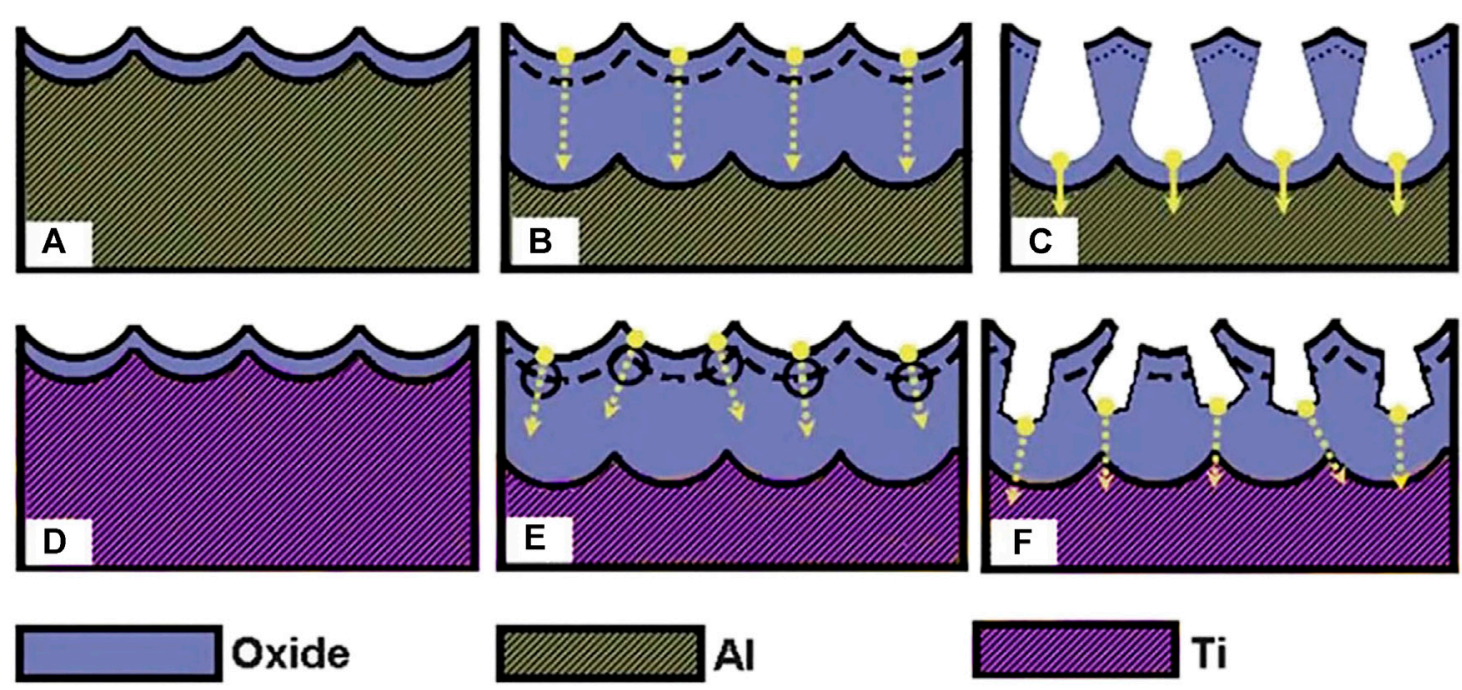

FIGURE 3 | Schematic graphs illustrating typical pore initiation in anodization of aluminum (A-C) and titanium (D-F). Arrows indicate the potential directions of the pore growth (Su et al., 2012).

interface, possibly producing large enough voids at inter-pore area to cause pore separation.

\section{OPTICAL BIOSENSORS BASED ON AAO}

Because of their porous architecture, use of nanoscaled materials as become more and more popular in various fields of research. For example, AAO can be used to produce optical sensing active or passive platforms with capability for guiding, reflecting, absorbing, transmitting, emitting, confining, or enhancing incident optical waves emitted by a source. During the previous decade, the use of nanomaterials as optical sensing platforms has made it possible to develop optical sensing systems with outstanding capabilities and performance in terms of sensitivity, selectivity, versatility and applicability. Some examples of optical techniques successfully combined with nanomaterials are surface-enhanced Raman spectroscopy (SERS), surface plasmon resonance spectroscopy (SPR), localized surface-plasmon resonance spectroscopy (LSPR), reflectometric interference spectroscopy (RIFS), and photoluminescence (PL), summary shows in table 3.

\section{Surface-Enhanced Raman Scattering}

Surface-enhanced Raman scattering spectroscopy is an ultrasensitive optical technique based on enhancement of the Raman scattering that takes place when biomolecules are absorbed on metal film surfaces featuring nanostructured roughness (Le Ru et al., 2007; Lee et al., 2011; Kumar, 2012; Gandhiraman et al., 2014). A SERS-AAO based substrate can be fabricated by sputtering or evaporating a layer of plasmonic materials such as gold or silver nanoparticles (NPs) on either top or bottom surfaces (Huang and Tsai, 2019), achieving remarkable SERS enhancement from "hot spots" (Manikas et al., 2014; Duan et al., 2011; Freeman et al., 1995; kneipp et al., 1997). Other approaches, including metallic membranes, decoration of nanopores with nanoparticles, and growth of nanowires, have also been used to produce AAO-based SERS substrates, (Grimes, 2007; Anglin et al., 2008).

Two theories, viz., electromagnetic enhancement (EM) and chemical enhancement (CM), have been used to explain the exact enhanced mechanism of SERS effect. In general, these two theories work in concert on the substrate, with EM enhancement playing the dominant role in terms of contribution to SERS enhancement. The most convincing explanation in terms of EM enhancement involves a localized surface plasmon resonance effect. When an external electromagnetic wave interacts with free electrons on a metal surface, the collective electrons will oscillate at the junction of the metal surface and the electromagnetic wave. When the oscillation frequencies for the free electron on the metal surface and the electromagnetic wave become equal, surface plasma will be generated. Since the intensity of the Raman signal is proportional to the fourth power of the electromagnetic field intensity, it makes a major contribution to the EF up to $10^{4}-10^{7}$ (Li et al., 2010). In CM enhancement, charge transfer complexes are formed between chemical probe molecules and substrates, and $\mathrm{CE}$ is enhanced when the excitation frequency comes into resonance with charge transfer transitions (Zhao et al., 2018).

Over the years, SERS-AAO biosensors have become widely used in biomedical research and disease diagnose applications involving biological tissue, DNA, serum, and cancer cells ( $\mathrm{Su}$ et al., 2019; Yang et al., 2019; Zhou et al., 2019). SERS-AAO biosensors exhibit high selectivity, high sensitivity, real-time sampling, and capability for non-destructive testing.

Zhang et al. used the Lee-Meisel method to fabricate a sandwich structured with silver nanoparticles (SNPs) and silver nanoarrays (Zhang et al., 2011), using this structure to probe molecular series concentrations of resonant (Rhodamine $6 \mathrm{G})$ and non-resonant (melamine) structures. The intensity of the 
TABLE 3 | The analytical performance of the optical biosensors by using AAO

\begin{tabular}{|c|c|c|c|c|c|}
\hline Method & Sensing substrate & Analyte & LOD & Linear range & References \\
\hline \multirow[t]{14}{*}{ SERS } & Au decorated Ag nanobranches & R6G & $10^{-6} \mathrm{M}$ & $\mathrm{N} / \mathrm{A}$ & $\begin{array}{l}\text { Kim et al. } \\
(2017 a)\end{array}$ \\
\hline & Au coated polystyrene nanopillars & 4-Methyl benzene thiol & $10^{-9} \mathrm{M}$ & $10^{-9}-10^{-3} \mathrm{M}$ & $\begin{array}{l}\text { Kim et al. } \\
(2017 b)\end{array}$ \\
\hline & Ag decorated AAO & 4-Mercaptopyridine & $10^{-6} \mathrm{M}$ & $10^{-6}-10^{-3} \mathrm{M}$ & Ji et al. (2009) \\
\hline & Sandwiched substrate (analyte molecules & $\mathrm{R} 6 \mathrm{G}$ & $10^{-19} \mathrm{M}$ & $10^{-19}-10^{-9} \mathrm{M}$ & Zhang et al. \\
\hline & embedded between Ag nanoarrays and Ag NPs) & Melamine & $10^{-9} \mathrm{M}$ & $10^{-9}-10^{-3} \mathrm{MV}$ & $(2011)$ \\
\hline & Ag dendrite integrated AAO membrane & $\mathrm{R} 6 \mathrm{G}$ & $10^{-11} \mathrm{M}$ & $10^{-11}-10^{-5} \mathrm{M}$ & $\begin{array}{l}\text { Zhang et al. } \\
(2016)\end{array}$ \\
\hline & Metallic glassy nanowire arrays & Rhodamine B & $10^{-6} \mathrm{M}$ & $10^{-5}-10^{-9} \mathrm{M}$ & Liu et al. (2014a) \\
\hline & Ag-AAO NPs arrays & Adenine & $10^{-4} \mathrm{M}$ & N/A & $\begin{array}{l}\text { Chan et al. } \\
(2017)\end{array}$ \\
\hline & Ag-NPs-decorated germanium nanocap arrays & R6G & $10^{-11} \mathrm{M}$ & $10^{-11}-10^{-6} \mathrm{M}$ & Liu et al. (2014b) \\
\hline & Transparent substrate with Ag-Nps & Ractopamine residue on pork meat & $10^{-8} \mathrm{M}$ & $10^{-8}-10^{-3} \mathrm{M}$ & Yan et al. (2018) \\
\hline & \multirow[t]{4}{*}{$\begin{array}{l}\text { AAO-based multiplex vertical flow assay with Raman } \\
\text { dye encoded core-shell -SERS nanotags }\end{array}$} & $\mathrm{CRP}$ & $\begin{array}{c}53.4 \mathrm{fg} / \\
\mathrm{ml}\end{array}$ & $3.57-547.01 \mathrm{ng} \mathrm{ml}^{-1}$ & $\begin{array}{l}\text { Chen et al. } \\
(2020)\end{array}$ \\
\hline & & IL-6 & $\begin{array}{c}4.72 \mathrm{fg} / \\
\mathrm{ml}\end{array}$ & $5.02-386.24 \mathrm{ng} \mathrm{ml}^{-1}$ & \\
\hline & & SAA & $\begin{array}{c}48.3 \mathrm{fg} / \\
\mathrm{ml}\end{array}$ & $7.53-517.61 \mathrm{ng} \mathrm{ml}^{-1}$ & \\
\hline & & PCT & $\begin{array}{c}7.53 \mathrm{fg} / \\
\mathrm{ml}\end{array}$ & $6.35-278.72 \mathrm{ng} \mathrm{ml}^{-1}$ & \\
\hline \multirow[t]{6}{*}{ SPR } & A golddeposited AAO substrate & CRP antigen & $1 \mathrm{fg} / \mathrm{ml}$ & $1 \mathrm{fg} / \mathrm{ml}-100 \mu \mathrm{g} / \mathrm{ml}$ & $\begin{array}{l}\text { Yeom et al. } \\
(2011)\end{array}$ \\
\hline & GNRs (gold nanorods) & Escherichia coli O157:H7 & $\begin{array}{c}100 \mathrm{ag} / \\
\mathrm{ml}\end{array}$ & $\begin{array}{l}100 \mathrm{ag} / \mathrm{ml}- \\
10^{5} \mathrm{cfu} / \mathrm{ml}\end{array}$ & Eum et al. (2010) \\
\hline & Au-capped nanopillar plasmonic biosensor & Human immunoglobulin & $1 \mathrm{ng} / \mathrm{ml}$ & $1 \mathrm{ng} / \mathrm{ml}-100 \mathrm{ug} / \mathrm{ml}$ & $\begin{array}{l}\text { Saito et al. } \\
\text { (2012) }\end{array}$ \\
\hline & Gold nano-ellipsoid arrays & Transmembrane protein CD63 & $1 \mathrm{ng} / \mathrm{ml}$ & $1 \mathrm{ng} / \mathrm{ml}-10^{3} \mathrm{ng} / \mathrm{ml}$ & Lv et al. (2019) \\
\hline & Gold-capped nanostructures & $\lg A$ & $10 \mathrm{ng} / \mathrm{\mu L}$ & $10 \mathrm{ng} / \mu \mathrm{l}-500 \mathrm{ng} / \mu \mathrm{L}$ & Ali et al. (2018) \\
\hline & Cyclo-olefin polymer (COP) & Cell interleukin-6 & $10 \mathrm{ng} / \mathrm{ml}$ & 10 ng/ML-100 ng/ml & Luo et al. (2020) \\
\hline \multirow[t]{6}{*}{ RIFS } & Nanopore thin film & Theophylline & $0.05 \mu \mathrm{M}$ & $0.05-48 \mu \mathrm{M}$ & $\begin{array}{l}\text { Feng et al. } \\
(2018)\end{array}$ \\
\hline & Porous thin film & $\mathrm{TNF}-\alpha$ & $\begin{array}{c}0.13 \mu \mathrm{g} / \\
\mathrm{ml}\end{array}$ & $100-1500 \mathrm{ng} / \mathrm{ml}$ & $\begin{array}{l}\text { Rajeev et al. } \\
(2018)\end{array}$ \\
\hline & Au-coated nanopore thin film & Salicylic acid & $0.1 \mu \mathrm{M}$ & $0.1-100 \mu \mathrm{M}$ & $\begin{array}{l}\text { Chen et al. } \\
\text { (2019) }\end{array}$ \\
\hline & Au-coated nanopore thin film & Abscisic acid and salicylic acid & $0.1 \mu \mathrm{M}$ & $0.1-200 \mu \mathrm{M}$ & $\begin{array}{l}\text { Feng et al. } \\
(2020)\end{array}$ \\
\hline & Au-coated nanopore thin film & $\begin{array}{l}\text { Insulin, glutamic acid decarboxylase (GAD) } \\
\text { insulinoma associated protein-2 (IA-2) }\end{array}$ & $\begin{array}{c}0.05 \mathrm{U} / \\
\mathrm{ml}\end{array}$ & $0.1 \mathrm{U} / \mathrm{ml}-50 \mathrm{U} / \mathrm{ml}$ & Mao et al. (2019) \\
\hline & Au-coated nanopores & Gentamicin sulfate (GS) & $\mathrm{N} / \mathrm{A}$ & $\mathrm{N} / \mathrm{A}$ & $\begin{array}{l}\text { Song et al. } \\
(2017)\end{array}$ \\
\hline \multirow[t]{3}{*}{$\mathrm{PL}$} & Au-coated nanopore thin film & Staphylococcus aureus & $2 \mathrm{CFU} / \mathrm{ml}$ & 0-2000 CFU/ml & Pla et al. (2020) \\
\hline & Nanoporous anodic alumina & Cocaine & $0.5 \mu \mathrm{M}$ & $0.5 \mu \mathrm{M}-1 \mathrm{mM}$ & $\begin{array}{l}\text { Ribes et al. } \\
(2016)\end{array}$ \\
\hline & Nanoporous anodic alumina & $\begin{array}{l}\text { D-glucose } \\
\text { L-cysteine }\end{array}$ & $0.010 \mathrm{M}$ & 0-1200 m mol/L & $\begin{array}{l}\text { Santos et al. } \\
\text { (2013b) }\end{array}$ \\
\hline
\end{tabular}

diagnostic peak of R6G and melamine decreased with decreasing molecular concentration. The limit of detection (LOD) for R6G was $10^{-19} \mathrm{M}$ and for melamine was $10^{-9} \mathrm{M}$. The AAO-based SERS sensor for the sandwich structure exhibited excellent reproducibility and good stability and could be used for quantitative analysis. Liu et al. fabricated highly ordered AgNPs@Ge nanocap arrays based on an AAO template and a uniform SERS substrate (Liu J. et al., 2014;Figure 4A) to detect the R6G, with AAO-based SERS sensors exhibiting very good biocompatibility, structural stability, and sensitivity (Xue et al., 2011; Prabakar et al., 2010; Liu et al., 2014b; Fan and Chu, 2010; Alvarez et al., 2009b). Using a hybrid SERS substrate, the
LOD for R6G is $10^{-11} \mathrm{M}$. Zhang et al. described a large-scale Ag dendrite-integrated AAO membrane used as a 3D SERS-active substrate, and advantages of these $3 \mathrm{D}$ structure were to generate a special overlap with intense and uniform fields and to provide a large metallic surface (Figure 5; Zhang et al., 2016).

Most of these nanostructured SERS substrates are nontransparent, limiting many SERS applications (Yan et al., 2018). Yan et al., fabricated the transparent SERS substrate based on AAO shown in Figure 6; after the first anodization process was finished, phosphoric acid could be used to etch the $\mathrm{Al}$ template and remove the porous alumina layer, followed by a four-step process of anodization and etching to fabricate conical 


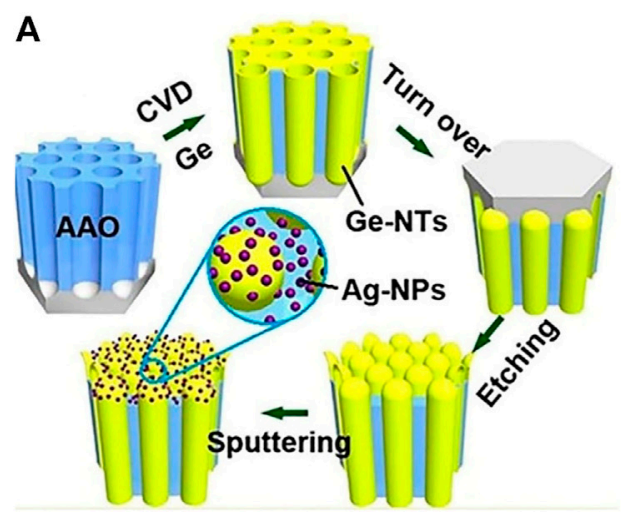

B

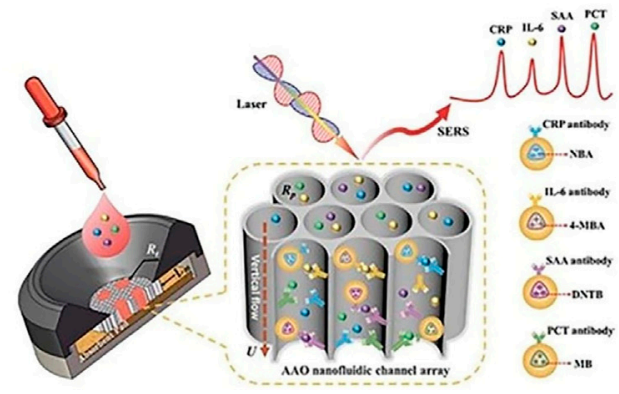

FIGURE 4 | (A)Schematic for the fabrication of Ag-NPs @ Ge-nanocap arrays protruding from AAO template (Liu et al., 2014a); (B) Schematic illustration of nanoporous AAO-based multiplex vertical flow assay (VFA) for the detection of four inflammatory biomarkers with Raman dyes encoded core-shell SERS nanotags. Characteristic Raman peaks of NBA at $593 \mathrm{~cm}^{-1}$, 4-MBA at $1,075 \mathrm{~cm}^{-1}$, DNTB at $1,341 \mathrm{~cm}^{-1}$, and MB at 1,621 $\mathrm{cm}^{-1}$, are used to encode CRP, IL-6, SAA, and PCT, respectively (Chen et al., 2020).

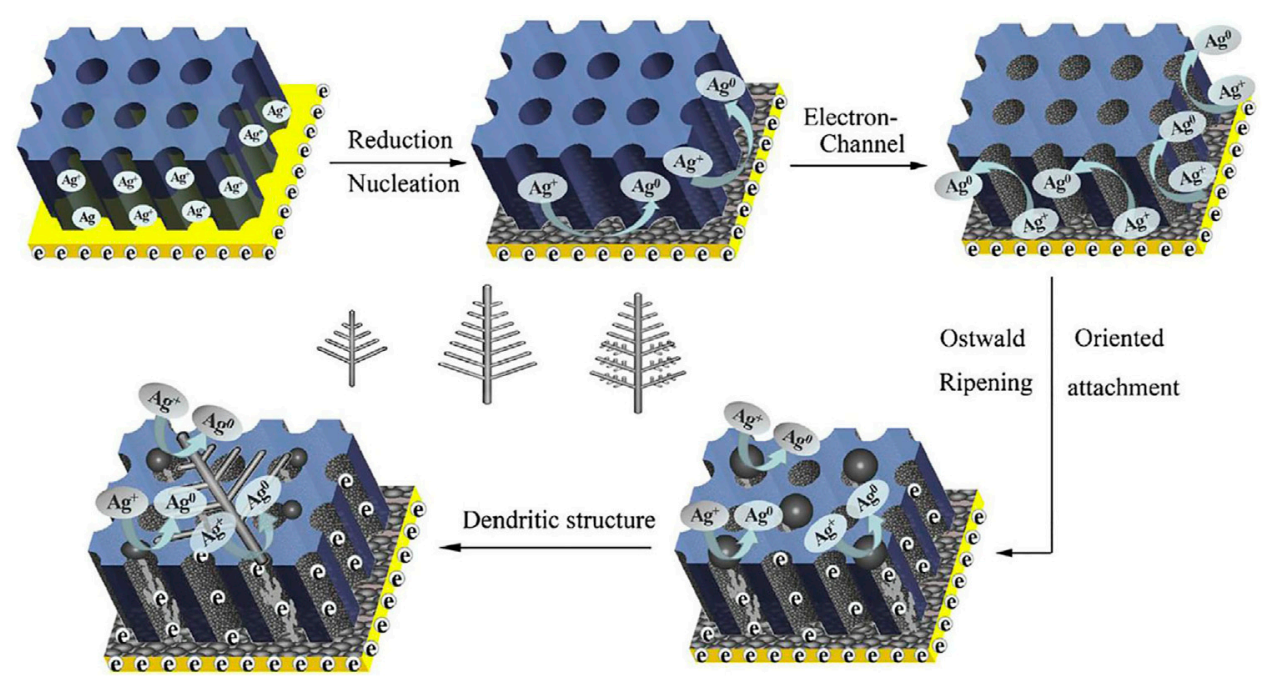

FIGURE 5 | Schematic representation of the proposed growth of silver dendritic (Zhang et al., 2016).

pores with nanotips. A $\mathrm{SnCl}_{4}$ aqueous solution was then used to remove the aluminum, and the template became transparent, after which a Ag-NPs layer was sputtered onto it. Such a transparent SERS substrate can be used to examine analytes in opaque substances such as ractopamine residue on pork. That paper described detecting ractopamine over a range from $10^{-4} \mathrm{M}-10^{-8} \mathrm{M}$. Such measurements can directly detect chemicals in opaque media with good specificity and they have potential to measure other trace chemicals on food surfaces.

Point-of-care testing (POCT) is an important diagnostic tool with several key advantages, including rapid data availability, reduced time, small sample volume for a large test menu, and robustness in detection of various biomarkers without falsenegative effects (Kim et al., 2017a). Chen and Sailor, 2011 developed the micro-array shown in Figure 4B, an AAO $(2 \times$ 2)-based SERS sensor for detecting $C$ reactive protein, interleukin-6, serum amyloid $A$, and procalcitonin by modifying capture antibodies (Chen et al., 2020). The researcher first immobilized antibodies on a $2 \times 2$ test array, then dyed encoded core-shell SERS nanotags. $A u^{N B A} @ A g, A u^{4-M B A} @ A g, A u^{D N T B} @ A g$, and $A u^{M B} @ A g \quad$ were used as labels for detection of CRP, IL-6, SAA, and PCT, respectively, subsequently detected using a Raman spectrometer. All four of these inflammatory biomarkers can be detected over a linear dynamic range spanning at least five orders of magnitude, and the authors used different AAO pore sizes $(140,170,250,300,350$, and $390 \mathrm{~nm})$ to detect the CRP biomarkers. Based on this experiment, and comparing with respect to SERS intensity, they found that a $350 \mathrm{~nm}$ AAO pore size and a $785 \mathrm{~nm}$ laser exhibited optimum performance. They finally compared the sensitivity of an AAO membrane to that of an NC membrane for detecting biomarkers, with results showing 


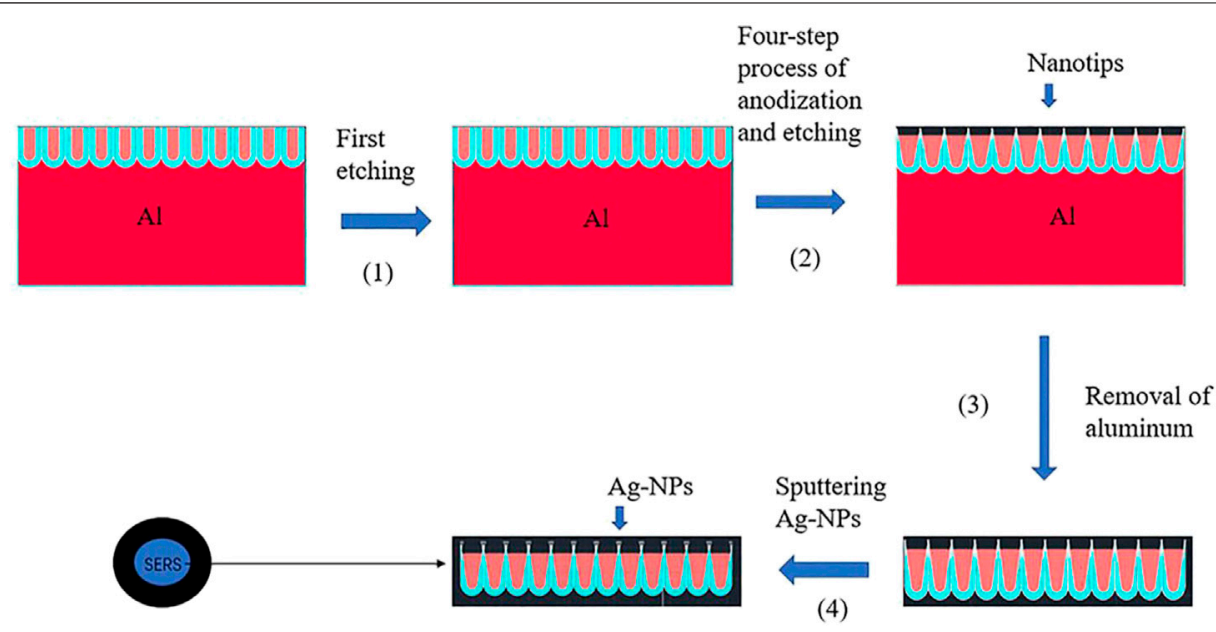

FIGURE 6 | Schematic for the fabrication of transparent substrate with Ag-NPs.

that the AAO membrane could accumulate more immune complexes and reduce non-specific absorption. This experiment illustrated that micro-array AAO-based SERS VFA can be used for multiplexed detection of inflammatory biomarkers with high sensitivity.

\section{Surface Plasmon Resonance}

Surface plasmon resonance, whose first application in 1982 was for SPR used in a biologic sensor (Liedberg et al., 1983), is based on generation of surface plasmons from an evanescent electromagnetic wave, a phenomenon that occurs when a light beam is focused on the surface of a prism coated with a thin metallic film. SPR sensors are widely used for detection of biological and chemical analytes, environmental monitoring, and medical diagnostics (Huber et al., 1999), with SPR-based biosensors exhibiting several advantages over other sensing methods. SPR exhibits excellent sensitivity either when the refractive index (RI) changes on the metal-dielectric interface or when molecular interaction occurs, and it can yield real-time kinetics information. Finally, by using defocused laser illumination and a charge-coupled device (CCD) camera as a detector, SPR can measure the intensity distribution in a large surface area with multiple sensing spots; this is called SPR imaging (SPRi).

AAO structures can be used to develop unique SPR sensing systems using localized surface plasmon resonances (LSPR). LSPR can be generated by various nanostructures, including gold nanodisks (Dahlin et al., 2009), nanoshells (Hirsch et al., 2003), nanorings (Larsson et al., 2007), and nanoholes (Rindzevicius et al., 2005) in thin films. In contrast to a SPR, a LSPR does not require a prism or a goniometer, meaning that an LSPR can be used in less complex equipment. Figure 7 depicts the principle of LSPR phenomena and optical interferometry using an antigen-antibody-conjugated AAO chip (Yeom et al., 2011; Willets and Van Duyne, 2007; Kelly et al., 2003; Miller and Lazarides, 2005). The light illuminates the sensor, and reflected light from an $\mathrm{Au}$ sheet and the bottom of the Al substrate will interfere by interacting with both constructive and destructive interference to form an interference wave (Huang et al., 2011). Equation 9 (Whitney et al., 2005) shows that once a target has been immobilized on the sensor, it will change the effective index of refraction and in turn the effective optical thickness, resulting in changes in the reflected wavelength.

$$
\Delta \lambda_{\max }=m \Delta n\left[1-e^{\left(-2 d / l_{d}\right)}\right]
$$

In Eq. 9, $\Delta \lambda_{\max }$ is the wavelength shift, $m$ is the refractive index sensitivity, $\Delta n$ is the change in refractive index induced by adsorption, $\mathrm{d}$ is the effective thickness of the layer, and $l_{d}$ is the characteristic length of the electromagnetic-field decay. According to Eq. 9, LSPR can measure small changes in the interfacial refractive index of the AAO surface (Kim et al., 2017b). The most commonly used method to produce AAO-based LSPR systems is to grow a layer of AAO on the surface of a thin Al film deposited on the surface of the prism.

LSPR biosensors have attracted attention over the past decade by offering high sensitivity (Amanda et al., 2004), a small footprint (Chen et al., 2009), and non-chemical labeling (Hammond et al., 2014; Kim et al., 2017c). Capability for spontaneous detection gives the LSPR potential for diagnostic and point-of-care testing (POCT) (Endo et al., 2005; Acimovic et al., 2014; Chen et al., 2015; Yoshikawa et al., 2015; Oh et al., 2016). While there are many high-quality LSPR reviews (Anker et al., 2008; Jonsson et al., 2008; Petryayeva and Krull, 2011; Ringe et al., 2013; Cao et al., 2014; Estevez et al., 2014; Kim et al., 2015), in this section we focused on AAO-based LSPR biosensor.

The most common AAO-based LSPR biosensor for detecting CRP antigen was developed by Yeom et al., in 2011 (Yeom et al., 2011), who fabricated a uniform AAO substrate using two-step anodization, then deposited $5 \mathrm{~nm} \mathrm{Ni}$ and $15 \mathrm{~nm}$ Au layers on the AAO surface. The result (Figure 8) shows that reflected spectra from the membrane is shifted in response to variation in CRP antigen concentration; the graph depicts wavelengths between 600 and $780 \mathrm{~nm}$. Increasing the CRP antigen concentration 


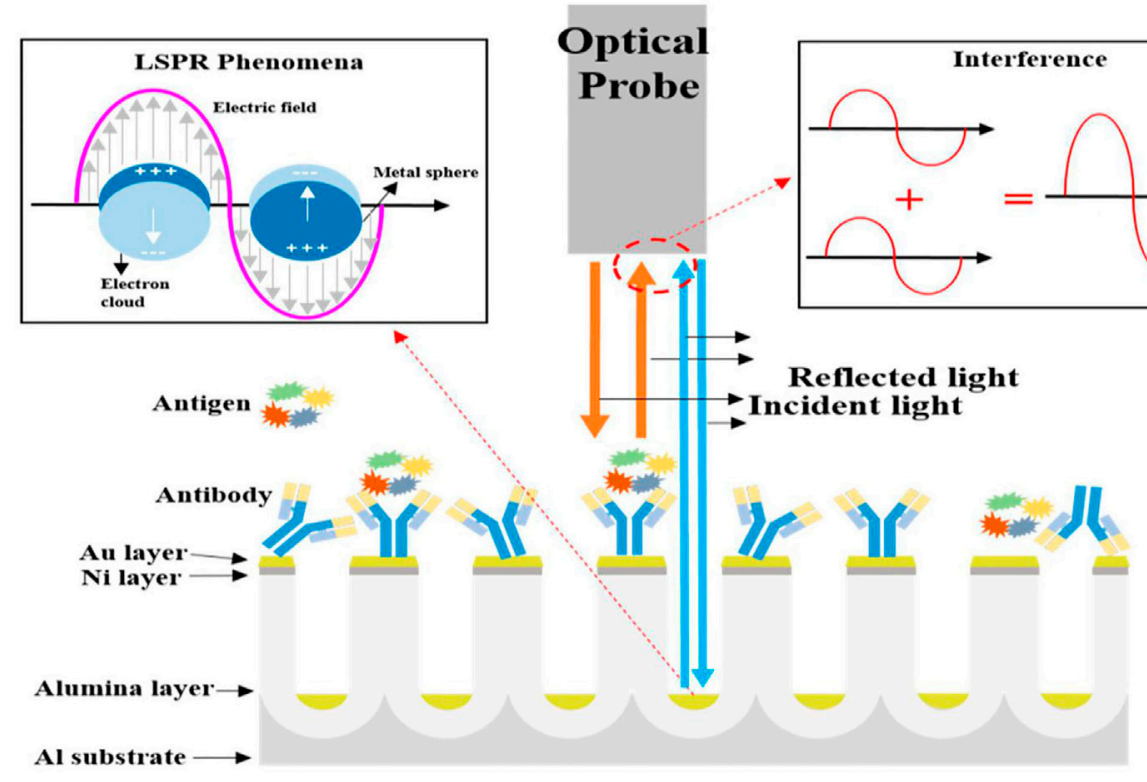

FIGURE 7 | Schematic diagrams representing localized surface plasmon resonance and optical interferometry in nano-porous nanostructures (Kim et al., 2017a).

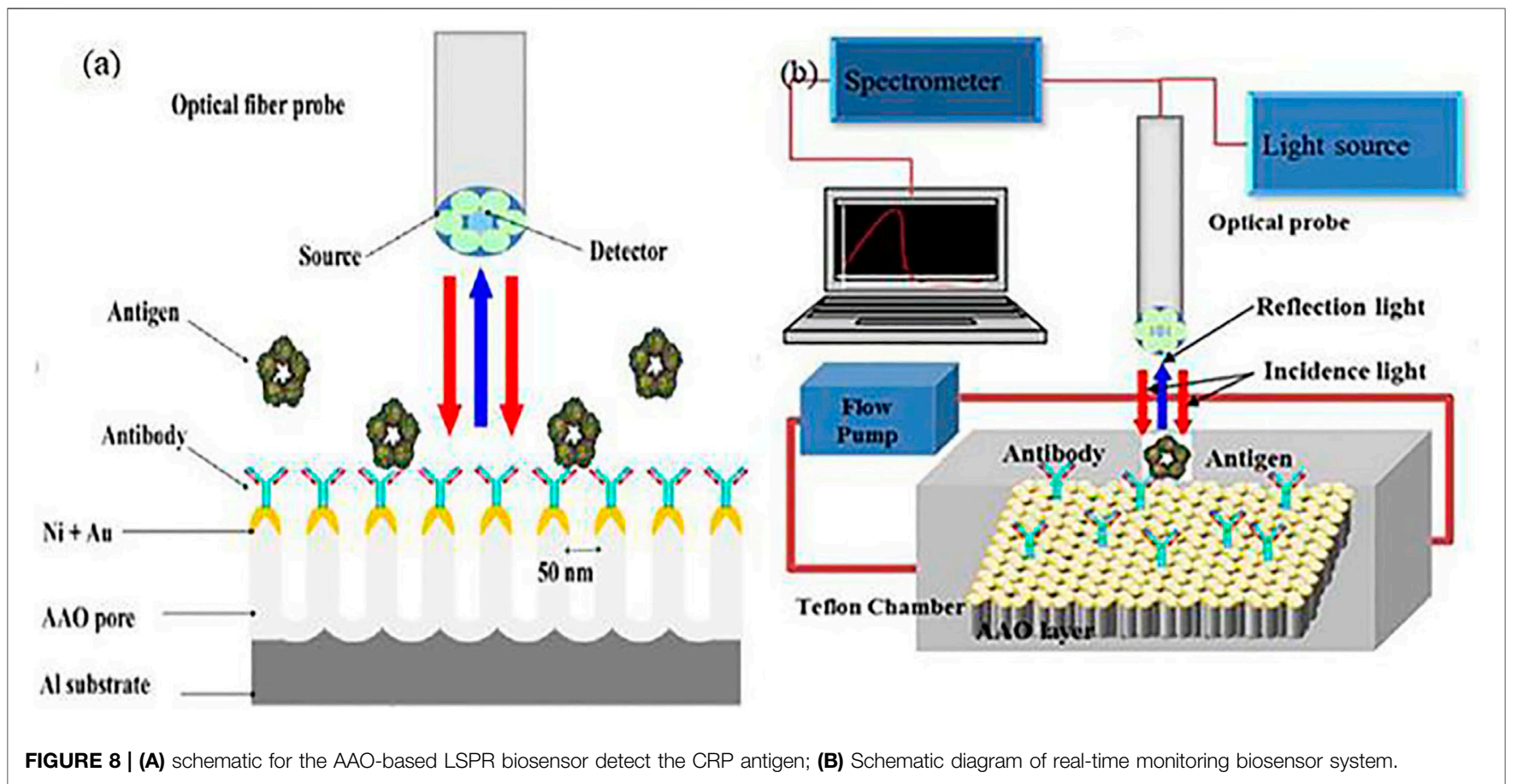

induces incremental increases in intensity, and the wavelength shifts with the reflectance spectra increasing as the log of antigen concentration, offering a large dynamic range and high sensitivity for quantitative detection of CRP antigen, with the $\lambda_{\max }$ of reflectance wavelength shifting dramatically with variations in CRP antigen concentration (from $1 \mathrm{fg} / \mathrm{ml}$ to $100 \mu \mathrm{g} / \mathrm{ml}$ ). To improve sensitivity, the group employed a sandwich assay method (Eum et al., 2010) using a GNP-labeled antibody for the sensor system (Yeom et al., 2013); the sensitivity of the sensor increased by 1.84 times and an LOD for a CRP antigen concentration of $100 \mathrm{ag} / \mathrm{ml}$.

Saito et al. (Saito et al., 2012), developed an AAO-based LSPR biosensor to detect Human immunoglobulin. They used nanoimprint lithography (NIL) molds to fabricate two types of 

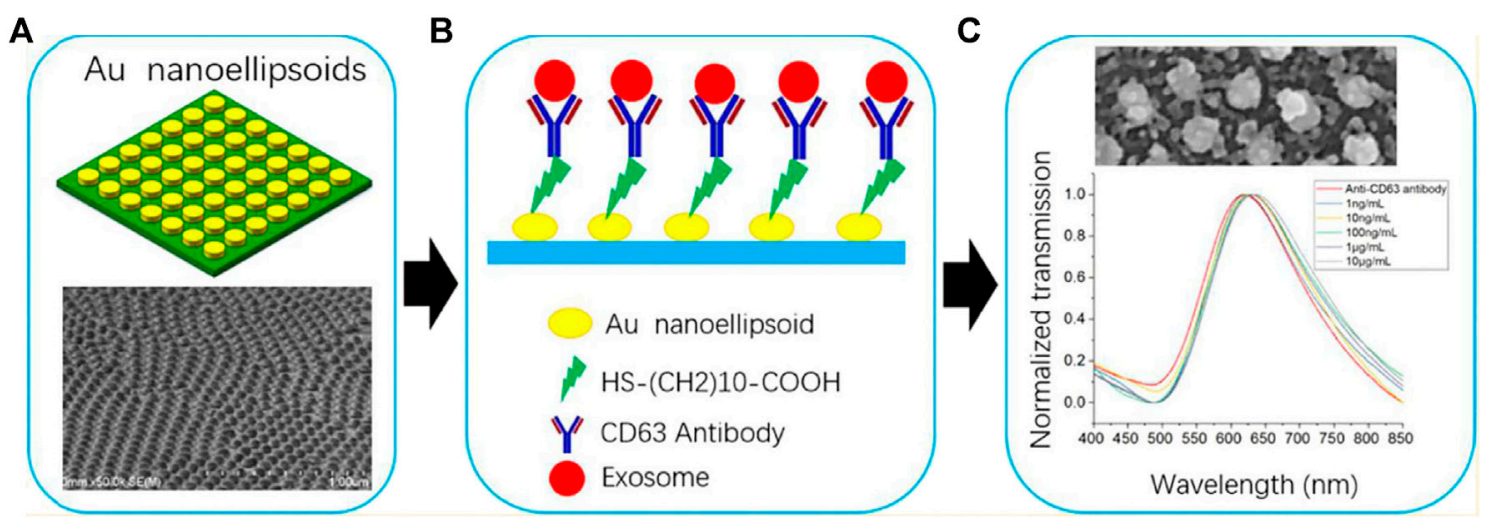

FIGURE 9 | (A) Schematic of LSPR-based biosensor; (B) Surface functionalization of biosensor; (C) Performance of the LSPR-based biosensor at different exosome concentrations.

$\mathrm{AAO}$, then transferred the $\mathrm{AAO}$ to a Cyclo-olefin polymer (COP) film surface, followed by sputtering a thin layer of gold onto the structure. A uniformly distributed Au-NPs structure that could enhance the signal-to-noize ratio by reducing the nonspecific binding was fabricated. The detection limit for IgG was $1.0 \mathrm{ng} / \mathrm{ml}$. In a further study, a microwell array and a nanopillar structure were integrated into a single substrate to enhance the device's biosensing capability, resulting in a detection limit for anti-IgA of $10 \mathrm{ng} / \mu \mathrm{L}$ (Ali et al., 2018). To improve biosensor sensitivity, the same group fabricated a COP-based LSPR sensor chip with a dense concave-convex nanostructure for generating "hotspots" on the surfaces of metallic nanoparticles (MNPs) (Luo et al., 2020), with an uneven nanostructure on the rough surface of the nanopillar fabricated by plasma etching (Kondyurin et al., 2006; Ting et al., 2010; Vesel and Semenic., 2012). Experiments detecting the cell cytokine indicated that the refractive index sensitivity was improved by the longer plasma etching time (Beeram and Zamborini, 2011; Ding et al., 2017; Luo et al., 2020).

A low-cost AAO-base LSPR biosensor was described by Lv's group in 2019 (Lv et al., 2019). They fabricated the nano-ellipsoid arrays combined with the microfluidic chip shown in Figure 9 to detect the anti-CD63 antibody. Different refractive index solutions (air, water, $1 \mathrm{M}$ glucose, ethanol, and $\mathrm{NaCl}$ ) were used to test the responses of the biosensor, with results indicating that the red shift of the extinction spectra was increased due to the refractive index of the sample. Different concentrations of exosomes were also detected, and the peak wavelength of the anti-CD63 antibody spectra increased as the exosome concentration increased. The detection limit was $1 \mathrm{ng} / \mathrm{ml}$.

\section{Reflectometric Interference Spectroscopy}

For various AAO dimensions, geometries, and chemical compositions, AAO structures exhibit characteristic responses when they interact with light. Many studies have described applications of AAO to surface profiling (Madani-Grasset et al., 2008; Debnath et al., 2009), metrology (Maniscalco et al., 2014), optical and chemical biosensors (Brecht et al., 1995), refractive index measurements for thin films (Buron et al., 2006), and many others (Jiang and Gerhard., 2001; Kim et al., 2007; Carter et al., 2011; Kaur et al., 2019). The RIFS spectrum of AAO produces fringes with well-resolved peaks generated by the Fabry-Perot effect (Alvarez et al., 2009a; Kuncser et al., 2011; Kumeria et al., 2012), whose equation is:

$$
O T_{e f f}=2 n_{e f f} \cdot L \cdot \cos \theta=m \lambda,
$$

where $n_{\text {eff }}$ is the effective refractive index of AAO, $L$ is the pore length (Ihmels et al., 2018), and $\mathrm{m}$ is the order of the RIfS fringe whose maximum is located at wavelength $\lambda$. Such peaks in the RIfS spectrum are useful for sensing because the binding molecules on the surface's inside pores will change the effective index of refraction and in turn change the effective optical thickness, causing a shift in dthe number of reflected interface fringes (Alvarez et al., 2009b).

Feng et al., focused on AAO-based RIFS biosensors for detecting plant chemicals, using AAO as an aptamer-based nanopore thin film sensor for detecting theophylline in a buffer solution and in complex fluids that included plant extracts and serum samples (Feng et al., 2018). Experimental results showed that the aptamer sensor not only exhibited good specificity and selectivity, but also had reasonable reusability with a significantly improved dynamic-detection range. Using $\sim 1 \mu \mathrm{L}$ plant extract or serum samples, the detection limit for theophylline was $0.05 \mu \mathrm{M}$. Low cost and ease of operation make this type of sensor suitable for point-of-care application in monitoring patient theophylline levels in real time. Such a biosensor also can also be used to detect tumor necrosis factor-alpha (TNF- $\alpha$ ) in buffer solution and in complex media (simulated wound fluid) using antiTNF- $\alpha$ antibodies (Rajeev et al., 2018). Based on the detection principle for the RIFS, when the TNF- $\alpha$ has reacted with antiTNF- $\alpha$ antibodies, the effective optical thickness (EOT) of the AAO thin film will change. TNF- $\alpha$ detection is achieved by monitoring EOT evolution with time, with a detection limit of $0.13 \mu \mathrm{g} / \mathrm{ml}$.

AAO nanopore structure also has potential for plant hormone detection. For example, plantaptamer (DNA) identification has been achieved using a AAO nanopore structure integrated within a microfluidic device (Chen et al., 2019). That paper introduced a structure-switching aptamer-based nanopore thin-film sensor developed for cost-effective, rapid, 

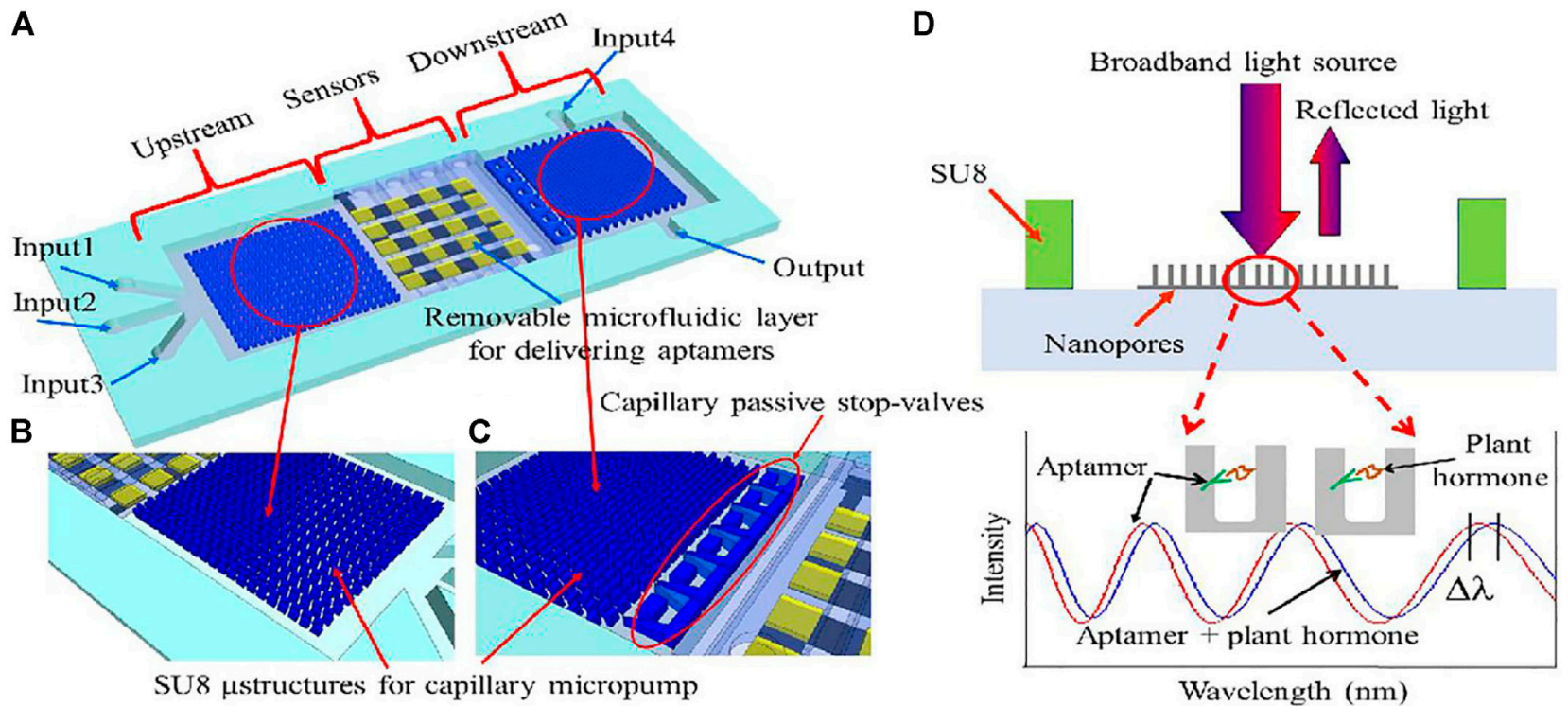

FIGURE 10 | (A) Schematic illustration of the chip. It consists of three main domains: capillary microfluidics for sample delivery in the upstream; the arrayed sensors region in the middle stream for detection of plant hormones; and capillary microfluidics for chip rinse in the downstream. (B) Close-up showing the SU-8 microstructures of the capillary micropump in the upstream. (C) Close-up showing the microstructures of the capillary micropump in the downstream and of the capillary passive stopvalves. (D) Optical sensor operational principle. Broadband light illuminates the sensor surface, the reflected optical interference fringes shift when plant hormone binds to its corresponding aptamer.

sensitive, and simple detection of SA in both buffer and plant extracts. A high-affinity SA aptamer was identified by immobilizing the SELEX library rather than the SA and by screening the library using a structure-switching SELEX approach. This nanosensor also exhibited good selectivity with respect to SA and its common metabolites. The performance of the AAO-based aptamer biosensor was statistically indistinguishable from that of HPLC.

To rapidly and efficiently detect various plant hormones, Feng et al. (Feng et al., 2020), developed a new chip equipped with aptamer-based sensors interfaced with a capillary microfluidics suitable for screening and detecting hormones in plant samples (Figure 10). Using this type of sensor, even if the hormones inside the sample are unknown, the sensor can screen or determine which type of plant hormones are in the samples. In this experiment, only an abscisic acid (ABA) aptamer and salicylic acid (SA) aptamer were functionalized on the sensor and they detected unknown samples containing ABA, SA, auxins, cytokinins, and gibberelline. The AAO-based RIFS biosensor exhibited high sensitivity, specificity, and reusability, offering a new cost-effective platform for potentially distinguishing and screening different plant hormones in raw plant samples.

Another multiplexed detection approach for detecting autoantibodies for Type 1 diabetes (T1D) panels was reported by Mao et al. (Mao et al., 2019). Their chip (Figure 11A,B) could simultaneously detect three autoantibodies in serum by functionalizing three different antigens (insulin, GAD, IA-2) on the sensors. These three autoantibodies were applied through Inlet 3, Inlet 4, and Inlet 5, so that each row had 3 sensors for use in detecting one autoantibody. Their results indicated that the optical signal increases with increased concentration of the three autoantibodies, and the detection limit for these three autoantibodies was $0.05 \mathrm{U} / \mathrm{ml}$.

Chao et al. (Song et al., 2017), reported drug loading and release enabled by the AAO nanopore thin film and layer-by-layer (LBL) nanoassembly shown in Figure 11C-E. In this experiment, gentamicin sulfate (GS), poly (acrylic acid) (PAA), and chitosan (CHI) were applied to the Au-coated AAO thin film device, followed by a [PAA/GS/PAA/CHI] combination applied ten times, representing a total of forty layers of chemicals deposited onto the nanopore thin film surface. During the drug-release process, the sample was immersed into flowing DI water and reflectance signals were used to measure the deposition of each chemical layer and the release procedure. During the loading process, the wavelength decreased (peak blueshift) during loading of the first two layers, but once the nanopore had been filled with chemicals, the chemicals can only deposit on the AAO surface, leading to a red shift. During the release process, the wavelength exhibited a blue shift. The peak shift was a red shift rather than a blue shift, suggesting that the chemicals/drug stored inside the nanopores were initially released into the DI water. Two different sizes of nanopore are were used in this experiment, and the results showed that drug release time and release dose can readily be further increased by simply adding LbL nanoassembly steps and/or increasing nanopore size and density.

\section{Photoluminescence-Based AAO Biosensors}

Photoluminescence spectroscopy can be used when light energy, or photons, stimulate the emission of a photon from any matter. 

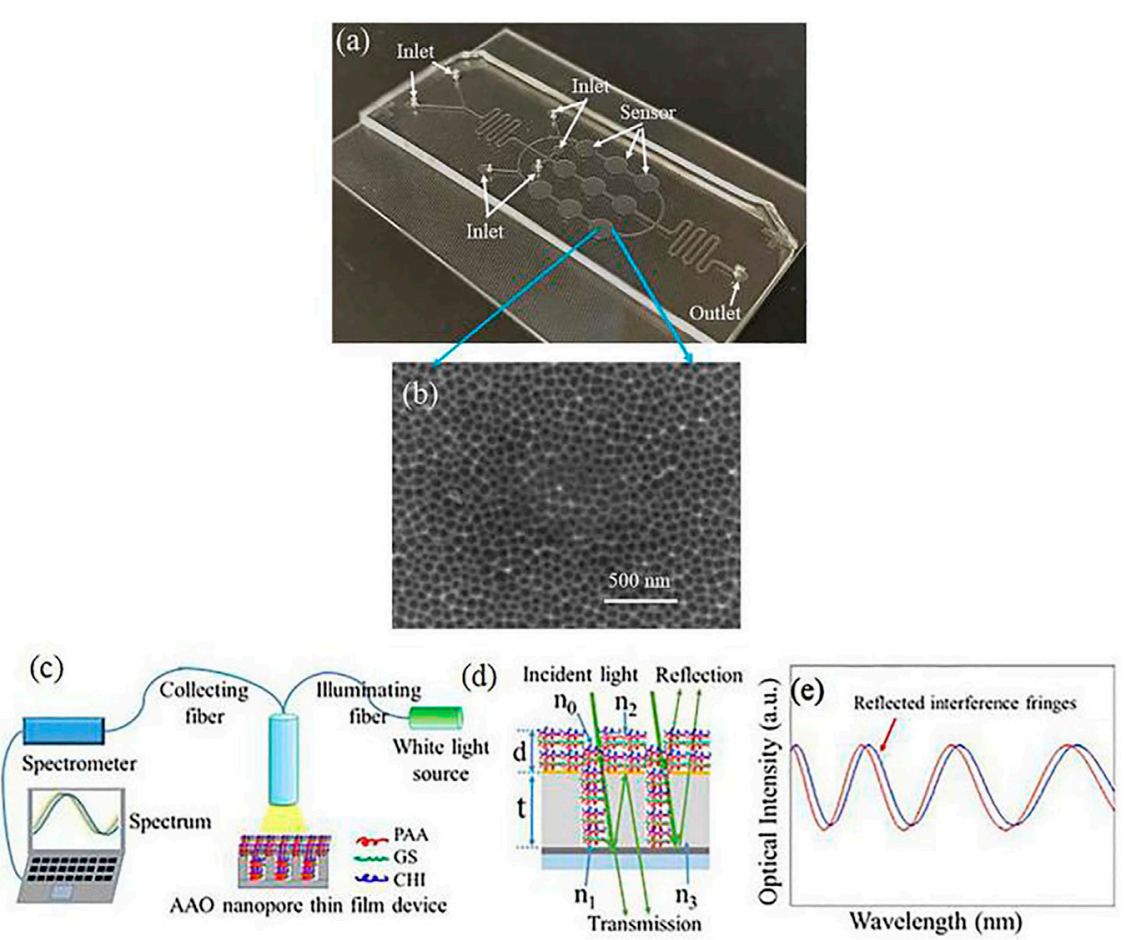

FIGURE 11 | (A) Photo of a fabricated chip containing 3-row nanopore thin film-based sensors; (B) SEM image showing the nanopores of the sensor; (C) Setup for optical monitoring of drug loading and release process for a nanopore thin film device; (D) incident light is reflected by the nanopore thin film device $(1<\mathrm{n} 0 \leq \mathrm{n} 2$, $1<\mathrm{n} 1 \leq \mathrm{n} 2,1.35<\mathrm{n} 2<1.58$ since the refractive indexes of PAA, $\mathrm{CH}$ and $\mathrm{GS}$ are $\mathrm{nPAA}=1.442, \mathrm{nCH}=1.35, \mathrm{nGS}=1.58, \mathrm{respectively}, \mathrm{n} 3=1.7, \mathrm{~d}=50 \mathrm{~nm}, \mathrm{t}=3 \mathrm{~mm}) ;(\mathrm{e})$ reflected light from the $\mathrm{AAO}$ nanopore thin film device is interference fringes as the transducing signals.

When light illuminating a sample is absorbed, a process called photon excitation can occur, causing the material to jump to a higher electronic state, then release energy, and finally return back to a lower energy level (Shen et al., 2004; Santos et al., 2013b). The photoluminescence process includes both fluorescence emission and phosphorescence emission. AAObased PL biosensors can be used to detect antibody-antigen bindings, enzyme-substrate digestions, and drug loading and release, and they have many applications in aplications such as nanoreactors, drug releasing nanochips, etc. (Casanova et al., 2008; Andrew et al., 2010; Ruminski et al., 2010; Chen et al., 2011). The optical principle for an AAO-based PL sensor, the Fabri-Pérot effect, is the same as for an AAO-based RIfS sensor.

Pla et al., used AAO to detect Staphylococcus aureus using the PLS method with rhodamine $B$, with the amount of released rhodamineB increasing with an increase in cocaine concentration. The signal representing the released rhodamine $\mathrm{B}$ was detected by a fluorescence spectrometer. and the author detected bacterial concentrations ranging from 0 to $2 \times 10_{3}$ in both PBS and clinical blood samples (Pla et al., 2020), reflecting an LOD of 2 CFU $m L^{-1}$ in PBS buffer and 5 CFU $m L^{-1}$ in blood media. Moreover, the probe demonstrated a high selectivity of $S$. aureus and did not respond to the presence of other Staphylococcus species. Martínez et al., used the same method to detect cocaine within concentrations ranging from $0.5 \mu \mathrm{M}$ to $1 \mathrm{mM}$, resulting in a LOD level of $0.5 \mathrm{M}$, with the sensor having a higher affinity for cocaine than morphine (Ribes et al., 2016).
The underlying optical principles for PLS-AAO and RIfSAAO are identical. Santos, et al. (Santos et al., 2013a), presented a comparative study of these two methods by detecting different analytes under distinct adsorption (Figure 12), using nanopore sizes for PLS-AAO and RIfS-AAO of $55 \pm 2$ and $47 \pm 2 \mathrm{~nm}$, respectively. Two experiments are described in this paper: 1) detection of D-glucose under nonspecific adsorption conditions, and 2) detection of L-cysteine under specific adsorption conditions, and the results showed that the PLS-AAO biosensor exhibited better performance in both experiments. The authors also summarized the main factors influencing the sensitivity of AAO-based biosensor that could explain the reason for PLS-AAO platform to be much more sensitive than the RIfSAAO platform for detection of D-glucose and L-cysteine.

\section{CONCLUSION}

This review paper mainly deals with optical techniques in combination with AAO platforms such as surface-Enhanced Raman Scattering (SERS), surface Plasmon Resonance (SPR), reflectometric Interference Spectroscopy (RIfS), and photoluminescence Spectroscopy (PL). An AAO-based optical biosensor exhibited simple and fast operation with very good selectivity specificity, and reusability, with a detection limit lower than current lab-based equipment. It also exhibited performance statistically indistinguishable from HPLC for measuring 

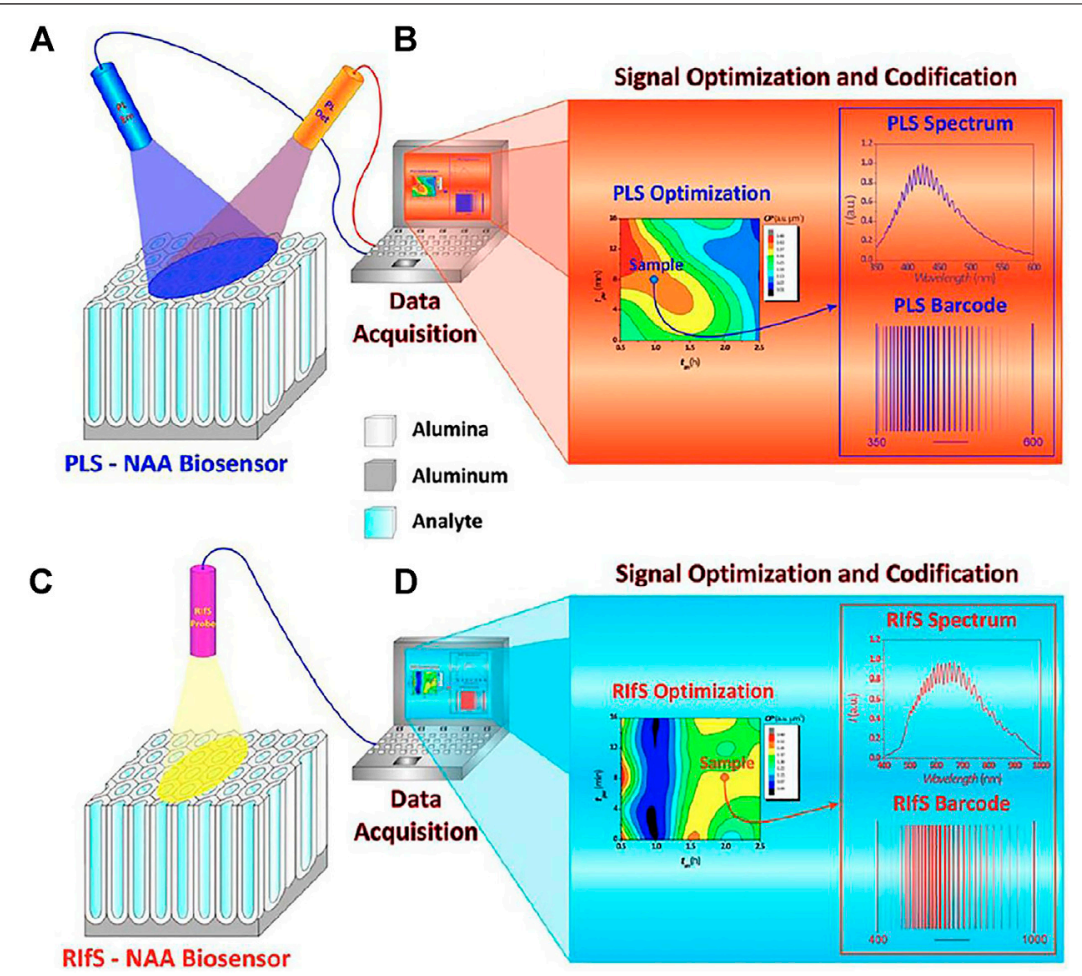

FIGURE 12 | Schematic diagram of PLS-NAA and RIfS-NAA biosensing platforms. (A) PLS-NAA sensing platform. (B) Optimization and conversion of each PLSNAA spectrum into an optical barcode. (C) RIfS-NAA sensing platform. (D) Optimization and conversion of each RIfS-NAA spectrum into an optical barcode.

concentrations of samples. AAO-based optical sensors and microfluidic chip can be combined to achieve multiplexed detection, even POCT, and we believe that AAO has huge remaining potential in many application areas such as nanotechnology, optics, medicine, and materials science.

\section{AUTHOR CONTRIBUTIONS}

SF planned this review paper, summarized the search, analyzed the results, and wrote this 485 review paper. WJ

\section{REFERENCES}

Aćimović, S. S., Ortega, M. A., Sanz, V., Berthelot, J., Garcia-Cordero, J. L., Renger, J., et al. (2014). LSPR Chip for Parallel, Rapid, and Sensitive Detection of Cancer Markers in Serum. Nano Lett. 14 (5), 2636-2641. doi:10.1021/nl500574n

Ali, R. A. M., Espulgar, W. V., Aoki, W., Jiang, S., Saito, M., Ueda, M., et al. (2018). One-step Nanoimprinted Hybrid Micro-/nano-structure for In Situ Protein Detection of Isolated Cell Array via Localized Surface Plasmon Resonance. Jpn. J. Appl. Phys. 57 (3S2), 03EC03. doi:10.7567/jjap.57.03ec03

Alkire, R. C., Gogotsi, Y., and Simon, P. (2008). Nanostructured Materials in Electrochemistry. John Wiley \& Sons.

Altomare, M., Cha, G., and Schmuki, P. (2020). Anodic Nanoporous Niobium Oxide Layers Grown in Pure Molten Ortho-Phosphoric Acid. Electrochimica Acta 344, 136158. doi:10.1016/j.electacta.2020.136158

Alvarez, S. D., Derfus, A. M., Schwartz, M. P., Bhatia, S. N., and Sailor, M. J. (2009a). The Compatibility of Hepatocytes with Chemically Modified Porous Silicon with Reference to In Vitro Biosensors. Biomaterials 30 (1), 26-34. doi:10.1016/j.biomaterials.2008.09.005 conducted the search of the relevant literature materials. All authors have 486 read and agreed to the published version of the manuscript.

\section{FUNDING}

Project supported by the Program for Innovative Teams of Outstanding Young and Middle-aged Researchers in the Higher Education Institutions of Hubei Province (Grant No. T2020014).

Alvarez, S. D., Li, C.-P., Chiang, C. E., Schuller, I. K., and Sailor, M. J. (2009b). A Label-free Porous Alumina Interferometric Immunosensor. Acs Nano 3 (10), 3301-3307. doi:10.1021/nn900825q

Amanda, J. H., Zou, S., George, C. S., and Richard, P. V. D. (2004). Nanoscale Optical Biosensor: Short Range Distance Dependence of the Localized Surface Plasmon Resonance of Noble Metal Nanoparticles. J. Phys. Chem. B 108 (22), 6961-6968. doi:10.1021/jp036261n

Andrew, J. S., Anglin, E. J., Wu, E. C., Chen, M. Y., Cheng, L., Freeman, W. R., et al. (2010). Sustained Release of a Monoclonal Antibody from Electrochemically Prepared Mesoporous Silicon Oxide. Adv. Funct. Mater. 20 (23), 4168-4174. doi:10.1002/adfm.201000907

Anglin, E., Cheng, L., Freeman, W., and Sailor, M. (2008). Porous Silicon in Drug

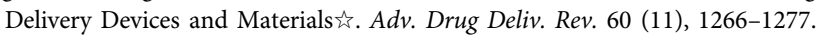
doi:10.1016/j.addr.2008.03.017

Anitha, V. C., Zazpe, R., Krbal, M., Yoo, J., Sopha, H., Prikryl, J., et al. (2018). Pt Nanoparticles Decorated TiO2 Nanotubes for the Reduction of Olefins. Appl. Mater. Today 10, 86-92. doi:10.1016/j.jcat.2018.06.017

Anker, J. N., Hall, W. P., Lyandres, O., Shah, N. C., Zhao, J., and Van Duyne, R. P. (2008). Biosensing with Plasmonic Nanosensors. Nat. Mater 7, 442-453. doi:10.1038/nmat2162 
Barton, J. E., Stender, C. L., Li, P., and Odom, T. W. (2009). Structural Control of Anodized Tantalum Oxide Nanotubes. J. Mater. Chem. 19 (28), 4896-4898. doi:10.1039/b904964a

Beeram, S. R., and Zamborini, F. P. (2011). Effect of Protein Binding Coverage, Location, and Distance on the Localized Surface Plasmon Resonance Response of Purified Au Nanoplates Grown Directly on Surfaces. J. Phys. Chem. C 115 (15), 7364-7371. doi:10.1021/jp2010869

Brecht, A., Piehler, J., Lang, G., and Gauglitz, G. (1995). A Direct Optical Immunosensor for Atrazine Detection. Analytica Chim. Acta 311 (3), 289-299. doi:10.1016/0003-2670(95)00120-o

Buron, C. C., Membrey, F., Filiâtre, C., and Foissy, A. (2006). A New Approach to Determine the Mean Thickness and Refractive Index of Polyelectrolyte Multilayer Using Optical Reflectometry. Colloids Surf. A: Physicochemical Eng. Aspects 289 (1-3), 163-171. doi:10.1016/j.colsurfa.2006.04.029

Cao, J., Sun, T., and Grattan, K. T. V. (2014). Gold Nanorod-Based Localized Surface Plasmon Resonance Biosensors: A Review. Sensors actuators B: Chem. 195, 332-351. doi:10.1016/j.snb.2014.01.056

Carter, M. C. D., Sorrell, C. D., and Serpe, M. J. (2011). Deswelling Kinetics of Color Tunable Poly(N-Isopropylacrylamide) Microgel-Based Etalons. J. Phys. Chem. B 115 (49), 14359-14368. doi:10.1021/jp207138f

Casanova, F., Chiang, C. E., Li, C.-P., Roshchin, I. V., Ruminski, A. M., Sailor, M. J., et al. (2008). Gas Adsorption and Capillary Condensation in Nanoporous Alumina Films. Nanotechnology 19 (31), 315709. doi:10.1088/0957-4484/19/31/315709

Chan, T. Y., Liu, T. Y., Wang, K. S., Tsai, K. T., Chen, Z. X., Chang, Y. C., et al. (2017). Sers Detection of Biomolecules by Highly Sensitive and Reproducible Raman-Enhancing Nanoparticle Array. Nanoscale Res. Lett. 12 (1), 344. doi:10. 1186/s11671-017-2121-x

Chen, C., Feng, S., Zhou, M., Ji, C., Que, L., and Wang, W. (2019). Development of a Structure-Switching Aptamer-Based Nanosensor for Salicylic Acid Detection. Biosens. Bioelectron. 140, 111342. doi:10.1016/j.bios.2019.111342

Chen, H., Sun, Z., Ni, W., Woo, K. C., Lin, H.-Q., Sun, L., et al. (2009). Plasmon Coupling in Clusters Composed of Two-Dimensionally Ordered Gold Nanocubes. Small 5 (18), 2111-2119. doi:10.1002/smll.200900256

Chen, M. Y., Klunk, M. D., Diep, V. M., and Sailor, M. J. (2011). Electric-FieldAssisted Protein Transport, Capture, and Interferometric Sensing in Carbonized Porous Silicon Films. Adv. Mater. 23 (39), 4537-4542. doi:10. 1002/adma.201102090

Chen, M. Y., and Sailor, M. J. (2011). Charge-gated Transport of Proteins in Nanostructured Optical Films of Mesoporous Silica. Anal. Chem. 83 (18), 7186-7193. doi:10.1021/ac201636n

Chen, P., Chung, M. T., McHugh, W., Nidetz, R., Li, Y., Fu, J., et al. (2015). Multiplex Serum Cytokine Immunoassay Using Nanoplasmonic Biosensor Microarrays. ACS nano 9 (4), 4173-4181. doi:10.1021/acsnano.5b00396

Chen, R., Du, X., Cui, Y., Zhang, X., Ge, Q., Dong, J., et al. (2020). Vertical Flow Assay for Inflammatory Biomarkers Based on Nanofluidic Channel Array and SERS Nanotags. Small 16 (32), 2002801. doi:10.1002/smll.202002801

Cherki, C., and Siejka, J. (1973). Study by Nuclear Microanalysis and O18 Tracer Techniques of the Oxygen Transport Processes and the Growth Laws for Porous Anodic Oxide Layers on Aluminum. J. Electrochem. Soc. 120 (6), 784. doi:10.1149/1.2403563

Dahlin, A. B., Chen, S., Jonsson, M. P., Gunnarsson, L., Käll, M., and Höök, F. (2009). High-Resolution Microspectroscopy of Plasmonic Nanostructures for Miniaturized Biosensing. Anal. Chem. 81 (16), 6572-6580. doi:10.1021/ac901175k

Debnath, S. K., You, J., and Kim, S.-W. (2009). Determination of Film Thickness and Surface Profile Using Reflectometry and Spectrally Resolved Phase Shifting Interferometry. Int. J. Precis. Eng. Manuf. 10 (5), 5-10. doi:10.1007/s12541-0090086-0

Despić, A., and Parkhutik, V. P. (1989). "Electrochemistry of Aluminum in Aqueous Solutions and Physics of its Anodic Oxide," in Modern Aspects of Electrochemistry (Boston, MA: Springer), 20, 401-503.

Diggle, J. W., Downie, T. C., and Goulding, C. W. (1969). Anodic Oxide Films on Aluminum. Chem. Rev. 69 (3), 365-405. doi:10.1021/cr60259a005

Ding, S.-Y., You, E.-M., Tian, Z.-Q., and Moskovits, M. (2017). Electromagnetic Theories of Surface-Enhanced Raman Spectroscopy. Chem. Soc. Rev. 46 (13), 4042-4076. doi:10.1039/c7cs00238f

Duan, H., Hu, H., Kumar, K., Shen, Z., and Yang, J. K. W. (2011). Direct and Reliable Patterning of Plasmonic Nanostructures with Sub-10-nm Gaps. ACS nano 5 (9), 7593-7600. doi:10.1021/nn2025868
Elia, P., Nativ-Roth, E., Zeiri, Y., and Porat, Z. E. (2016). Determination of the Average Pore-Size and Total Porosity in Porous Silicon Layers by Image Processing of SEM Micrographs. Microporous Mesoporous Mater. 225, 465-471. doi:10.1016/j.micromeso.2016.01.007

Endo, T., Yamamura, S., Nagatani, N., Morita, Y., Takamura, Y., and Tamiya, E. (2005). Localized Surface Plasmon Resonance Based Optical Biosensor Using Surface Modified Nanoparticle Layer for Label-free Monitoring of Antigen-Antibody Reaction. Sci. Tech. Adv. Mater. 6 (5), 491-500. doi:10.1016/j.stam.2005.03.019

Estevez, M.-C., Otte, M. A., Sepulveda, B., and Lechuga, L. M. (2014). Trends and Challenges of Refractometric Nanoplasmonic Biosensors: A Review. Analytica Chim. Acta 806, 55-73. doi:10.1016/j.aca.2013.10.048

Eum, N.-S., Yeom, S.-H., Kwon, D.-H., Kim, H.-R., and Kang, S.-W. (2010). Enhancement of Sensitivity Using Gold Nanorods-Antibody Conjugator for Detection of E. coli O157:H7. Sensors Actuators B: Chem. 143 (2), 784-788. doi:10.1016/j.snb.2009.09.054

Fan, J., and Chu, P. K. (2010). Group IV Nanoparticles: Synthesis, Properties, and Biological Applications. Small 6 (19), 2080-2098. doi:10.1002/smll. 201000543

Feng, S., Chen, C., Song, C., Ding, X., Wang, W., and Que, L. (2020). Optical Aptamer-Based Sensors for Detecting Plant Hormones. IEEE Sensors J 21, 5743-5750. doi:10.1109/JSEN.2020.3041266

Feng, S., Chen, C., Wang, W., and Que, L. (2018). An Aptamer Nanopore-Enabled Microsensor for Detection of Theophylline. Biosens. Bioelectron. 105, 36-41. doi:10.1016/j.bios.2018.01.016

Fialho, L., Almeida Alves, C. F., Marques, L. S., and Carvalho, S. (2020). Development of Stacked Porous Tantalum Oxide Layers by Anodization. Appl. Surf. Sci. 511, 145542. doi:10.1016/j.apsusc.2020.145542

Flamme, K., Popat, K. C., Leoni, L., Markiewicz, E., Tempa, T., Roman, B. B., et al. (2007). Biocompatibility of Nanoporous Alumina Membranes for Immunoisolation. Biomaterials 28 (16), 2638-2645. doi:10.1016/j. biomaterials.2007.02.010

Formentín, P., Catalán, Ú., Fernández-Castillejo, S., Alba, M., Baranowska, M., Solà, R., et al. (2015). Human Aortic Endothelial Cell Morphology Influenced by Topography of Porous Silicon Substrates. J. Biomater. Appl. 30 (4), 398-408. doi:10.1177/0885328215588414

Freeman, R. G., Grabar, K. C., Allison, K. J., Bright, R. M., Davis, J. A., Guthrie, A. P., et al. (1995). Self-assembled Metal Colloid Monolayers: an Approach to SERS Substrates. Science 267 (5204), 1629-1632. doi:10.1126/science.267.5204.1629

Gandhiraman, R. P., Nordlund, D., Jayan, V., Meyyappan, M., and Koehne, J. E. (2014). Scalable Low-Cost Fabrication of Disposable Paper Sensors for DNA Detection. ACS Appl. Mater. Inter. 6 (24), 22751-22760. doi:10.1021/am5069003

Grimes, C. A. (2007). Synthesis and Application of Highly Ordered Arrays of TiO2 Nanotubes. J. Mater. Chem. 17 (15), 1451-1457. doi:10.1039/b701168g

Hammond, J., Bhalla, N., Rafiee, S., and Estrela, P. (2014). Localized Surface Plasmon Resonance as a Biosensing Platform for Developing Countries. Biosensors 4 (2), 172-188. doi:10.3390/bios4020172

Hirsch, L. R., Jackson, J. B., Lee, A., Halas, N. J., and West, J. L. (2003). A Whole Blood Immunoassay Using Gold Nanoshells. Anal. Chem. 75 (10), 2377-2381. doi: $10.1021 /$ ac0262210

Hoar, T. P., and Mott, N. F. (1959). A Mechanism for the Formation of Porous Anodic Oxide Films on Aluminium. J. Phys. Chem. Sol. 9 (2), 97-99. doi:10. 1016/0022-3697(59)90199-4

Huang, C.-Y., and Tsai, M.-S. (2019). Tunable Silver Nanoparticle Arrays by Hot Embossing and Sputter Deposition for Surface-Enhanced Raman Scattering. Appl. Sci. 9 (8), 1636. doi:10.3390/app9081636

Huang, K., Li, Y., Wu, Z., Li, C., Lai, H., and Kang, J. (2011). Asymmetric Light Reflectance Effect in AAO on Glass. Opt. Express 19 (2), 1301-1309. doi:10. 1364/oe.19.001301

Huber, A., Demartis, S., and Neri, D. (1999). The Use of Biosensor Technology for the Engineering of Antibodies and Enzymes. J. Mol. Recognit. 12 (3), 198-216. doi:10.1002/(sici)1099-1352(199905/06)12:3<198::aid-jmr458>3.0.co;2-9

Ihmels, H., Jiang, S., Mahmoud, M. M. A., Schönherr, H., Wesner, D., and Zamrik, I. (2018). Fluorimetric Detection of G-Quadruplex DNA in Solution and Adsorbed on Surfaces with a Selective Trinuclear Cyanine Dye. Langmuir 34 (39), 11866-11877. doi:10.1021/acs.langmuir.8b02382

Jessensky, O., Müller, F., and Gösele, U. (1998). Self-organized Formation of Hexagonal Pore Arrays in Anodic Alumina. Appl. Phys. Lett. 72 (10), 1173-1175. doi:10.1063/1.121004 
Ji, N., Ruan, W., Wang, C., Lu, Z., and Zhao, B. (2009). Fabrication of Silver Decorated Anodic Aluminum Oxide Substrate and its Optical Properties on Surface-Enhanced Raman Scattering and Thin Film Interference. Langmuir 25 (19), 11869-11873. doi:10.1021/la901521j

Jiang, M., and Gerhard, E. (2001). A Simple Strain Sensor Using a Thin Film as a Low-Finesse Fiber-Optic Fabry-Perot Interferometer. Sensors Actuators A: Phys. 88 (1), 41-46. doi:10.1016/s0924-4247(00)00494-5

Jonsson, M. P., Dahlin, A. B., Jönsson, P., and Höök, F. (2008). Nanoplasmonic Biosensing with Focus on Short-Range Ordered Nanoholes in Thin Metal Films (Review). Biointerphases 3 (3), FD30-FD40. doi:10.1116/1.3027483

Kant, K., Yu, J., Priest, C., Shapter, J. G., and Losic, D. (2014). Impedance Nanopore Biosensor: Influence of Pore Dimensions on Biosensing Performance. Analyst 139 (5), 1134-1140. doi:10.1039/c3an01933k

Kaur, S., Law, C. S., Williamson, N. H., Kempson, I., Popat, A., Kumeria, T., et al. (2019). Environmental Copper Sensor Based on PolyethylenimineFunctionalized Nanoporous Anodic Alumina Interferometers. Anal. Chem. 91 (8), 5011-5020. doi:10.1021/acs.analchem.8b04963

Kazuhiro, H., Yamaguchi, A., and Teramae, N. (2010). Properties of a Metal Clad Waveguide Sensor Based on a Nanoporous-Metal-Oxide/metal Multilayer Film. Anal. Chem. 82 (14), 6066-6073. doi:10.1021/ac100654b

Kelly, K. L., Coronado, E., Zhao, L. L., and Schatz, G. C. (2003). The Optical Properties of Metal Nanoparticles: The Influence of Size, Shape, and Dielectric Environment.

Kim, C., Kim, S., Choi, J., Lee, J., Kang, J. S., Sung, Y.-E., et al. (2014). Blue TiO2 Nanotube Array as an Oxidant Generating Novel Anode Material Fabricated by Simple Cathodic Polarization. Electrochimica Acta 141, 113-119. doi:10.1016/j. electacta.2014.07.062

Kim, D.-K., Kerman, K., Saito, M., Sathuluri, R. R., Endo, T., Yamamura, S., et al. (2007). Label-free DNA Biosensor Based on Localized Surface Plasmon Resonance Coupled with Interferometry. Anal. Chem. 79 (5), 1855-1864. doi:10.1021/ac061909o

Kim, S.-W., Lee, J.-S., Lee, S.-W., Kang, B.-H., Kwon, J.-B., Kim, O.-S., et al. (2017a). Easy-to-fabricate and High-Sensitivity LSPR Type Specific Protein Detection Sensor Using AAO Nano-Pore Size Control. Sensors 17 (4), 856. doi:10.3390/s17040856

Kim, S. H., Oh, S. S., Kim, K. J., Kim, J. E., Park, H. Y., Hess, O., et al. (2015). Subwavelength Localization and Toroidal Dipole Moment of Spoof Surface Plasmon Polaritons. Phys. Rev. B 91 (3), 035116. doi:10.1103/physrevb.91. 035116

Kim, Y.-T., Schilling, J., Schweizer, S. L., Sauer, G., and Wehrspohn, R. B. (2017b). $\mathrm{Au}$ Coated Ps Nanopillars as a Highly Ordered and Reproducible Sers Substrate. Photon. Nanostructures - Fundamentals Appl. 25, 65-71. doi:10. 1016/j.photonics.2017.03.006

Kim, Y.-T., Schilling, J., Schweizer, S. L., and Wehrspohn, R. B. (2017c). High Density Ag Nanobranches Decorated with Sputtered Au Nanoparticles for Surface-Enhanced Raman Spectroscopy. Appl. Surf. Sci. 410, 525-529. doi:10. 1016/j.apsusc.2017.02.167

Kneipp, K., Wang, Y., Kneipp, H., Perelman, L. T., Itzkan, I., Dasari, R. R., et al. (1997). Single Molecule Detection Using Surface-Enhanced Raman Scattering (SERS). Phys. Rev. Lett. 78 (9), 1667-1670. doi:10.1103/ physrevlett.78.1667

Kondyurin, A., Gan, B., Bilek, M., Mizuno, K., and Mckenzie, D. (2006). Etching and Structural Changes of Polystyrene Films During Plasma Immersion Ion Implantation from Argon Plasma. Nucl. Instrum. Methods Phys. Res. 251 (2), 413-418. doi:10.1016/j.nimb.2006.06.027

Kumar, G. P. (2012). Plasmonic Nano-Architectures for Surface Enhanced Raman Scattering: a Review. J. Nanophotonics 6 (1), 064503. doi:10.1117/1.jnp.6. 064503

Kumeria, T., Kurkuri, M. D., Diener, K. R., Parkinson, L., and Losic, D. (2012). Label-free Reflectometric Interference Microchip Biosensor Based on Nanoporous Alumina for Detection of Circulating Tumour Cells. Biosens. Bioelectron. 35 (1), 167-173. doi:10.1016/j.bios.2012.02.038

Kumeria, T., and Losic, D. (2012). Controlling Interferometric Properties of Nanoporous Anodic Aluminium Oxide. Nanoscale Res. Lett. 7 (1), 1-10. doi:10.1186/1556-276x-7-88

Kumeria, T., Santos, A., and Losic, D. (2014). Nanoporous Anodic Alumina Platforms: Engineered Surface Chemistry and Structure for Optical Sensing Applications. Sensors 14 (7), 11878-11918. doi:10.3390/s140711878
Kuncser, C., Kuncser, A., and Antohe, S. (2011). Optical Path Difference behind of Spectacular Game of Light. Proced. - Soc. Behav. Sci. 15, 2890-2896. doi:10. 1016/j.sbspro.2011.04.209

Larsson, E. M., Alegret, J., Käll, M., and Sutherland, D. S. (2007). Sensing Characteristics of NIR Localized Surface Plasmon Resonances in Gold Nanorings for Application as Ultrasensitive Biosensors. Nano Lett. 7 (5), 1256-1263. doi:10.1021/nl0701612

Le Ru, E. C., Blackie, E., Meyer, M., and Etchegoin, P. G. (2007). Surface Enhanced Raman Scattering Enhancement Factors: a Comprehensive Study. J. Phys. Chem. C 111 (37), 13794-13803. doi:10.1021/jp0687908

Lee, C. H., Hankus, M. E., Tian, L., Pellegrino, P. M., and Singamaneni, S. (2011). Highly Sensitive Surface Enhanced Raman Scattering Substrates Based on Filter Paper Loaded with Plasmonic Nanostructures. Anal. Chem. 83 (23), 8953-8958. doi:10.1021/ac2016882

Lee, W., and Park, S.-J. (2014). Porous Anodic Aluminum Oxide: Anodization and Templated Synthesis of Functional Nanostructures. Chem. Rev. 114 (15), 7487-7556. doi:10.1021/cr500002z

Lee, W., Schwirn, K., Steinhart, M., Pippel, E., Scholz, R., and Gösele, U. (2008). Structural Engineering of Nanoporous Anodic Aluminium Oxide by Pulse Anodization of Aluminium. Nat. Nanotech 3 (4), 234-239. doi:10.1038/nnano. 2008.54

Li, X., Chen, G., Yang, L., Jin, Z., and Liu, J. (2010). Multifunctional Au-Coated TiO2 Nanotube Arrays as Recyclable SERS Substrates for Multifold Organic Pollutants Detection. Adv. Funct. Mater. 20 (17), 2815-2824. doi:10.1002/adfm. 201000792

Liedberg, B., Nylander, C., and Lunström, I. (1983). Surface Plasmon Resonance for Gas Detection and Biosensing. Sensors and actuators 4, 299-304. doi:10.1016/ 0250-6874(83)85036-7

Liu, J., Meng, G., Li, X., and Huang, Z. (2014a). Ag-Nanoparticle-Decorated Ge Nanocap Arrays Protruding from Porous Anodic Aluminum Oxide as Sensitive and Reproducible Surface-Enhanced Raman Scattering Substrates. Langmuir. 30 (46), 13964-13969. doi:10.1021/la5033338

Liu, X., Shao, Y., Tang, Y., and Yao, Ke-Fu. (2014b). Highly Uniform and Reproducible Surface-Enhanced Raman Scattering on Air-Stable Metallic Glassy Nanowire Array. Scientific Rep. 4, 5835. doi:10.1038/srep05835

Lohrengel, M. M. (1993). Thin Anodic Oxide Layers on Aluminium and Other Valve Metals: High Field Regime. Mater. Sci. Eng. R: Rep. 11 (6), 243-294. doi:10.1016/0927-796x(93)90005-n

Losic, D., Lillo, M., and Losic, D., Jr (2009). Porous Alumina with Shaped Pore Geometries and Complex Pore Architectures Fabricated by Cyclic Anodization. Small 5 (12), 1392-1397. doi:10.1002/smll.200801645

Losic, D., and Losic, D., Jr (2009). Preparation of Porous Anodic Alumina with Periodically Perforated Pores. Langmuir 25 (10), 5426-5431. doi:10.1021/ la $804281 \mathrm{v}$

Lu, Q., Hashimoto, T., Skeldon, P., Thompson, G. E., Habazaki, H., and Shimizu, K. (2005). Nanoporous Anodic Niobium Oxide Formed in Phosphate/glycerol Electrolyte. Electrochem. Solid-State Lett. 8 (5), B17-B20. doi:10.1149/1.1883865

Luo, X., Zhu, C., Saito, M., Espulgar, W. V., Dou, X., Terada, Y., et al. (2020). Cauliflower-like Nanostructured Localized Surface Plasmon Resonance Biosensor Chip for Cytokine Detection. Bull. Chem. Soc. Jpn. 98. doi:10. 1246/bcsj.20200088

Lv, X., Geng, Z., Su, Y., Fan, Z., Wang, S., Fang, W., et al. (2019). Label-Free Exosome Detection Based on a Low-Cost Plasmonic Biosensor Array Integrated with Microfluidics. Langmuir 35 (30), 9816-9824. doi:10.1021/ acs.langmuir.9b01237

Macias, G., Ferré-Borrull, J., Pallarès, J., and Marsal, L. F. (2015). Effect of Pore Diameter in Nanoporous Anodic Alumina Optical Biosensors. Analyst 140 (14), 4848-4854. doi:10.1039/c4an01408a

Madani-Grasset, F., Pham, N. T., Glynos, E., and Koutsos, V. (2008). Imaging Thin and Ultrathin Organic Films by Scanning White Light Interferometry. Mater. Sci. Eng. B 152 (1-3), 125-131. doi:10.1016/j.mseb.2008.06.004

Manikas, A. C., Romeo, G., Papa, A., and Netti, P. A. (2014). Highly Efficient SurfaceEnhanced Raman Scattering Substrate Formulation by Self-Assembled Gold Nanoparticles Physisorbed on Poly(N-Isopropylacrylamide) Thermoresponsive Hydrogels. Langmuir 30 (13), 3869-3875. doi:10.1021/la4048616

Maniscalco, B., Kaminski, P. M., and Walls, J. M. (2014). Thin Film Thickness Measurements Using Scanning White Light Interferometry. Thin Solid Films 550, 10-16. doi:10.1016/j.tsf.2013.10.005 
Mao, S., Feng, S., and Que, L. (2019). Detection of Autoantibodies for Type 1 Diabetes Using Label-free Optical Sensors," in 2019 20th International Conference on Solid-State Sensors, Actuators and Microsystems \& Eurosensors XXXIII (TRANSDUCERS \& EUROSENSORS XXXIII) (IEEE), 578-581.

Masuda, H., Asoh, H., Watanabe, M., Nishio, K., Nakao, M., and Tamamura, T. (2001). Square and Triangular Nanohole Array Architectures in Anodic Alumina. Adv. Mater. 13 (3), 189-192. doi:10.1002/1521-4095(200102)13: 3<189::aid-adma189>3.0.co;2-z

Masuda, H., and Fukuda, K. (1995). Ordered Metal Nanohole Arrays Made by a Two-step Replication of Honeycomb Structures of Anodic Alumina. Science 268, 1466-1468. doi:10.1126/science.268.5216.1466

Masuda, H., Yamada, H., Satoh, M., Asoh, H., Nakao, M., and Tamamura, T. (1997). Highly Ordered Nanochannel-Array Architecture in Anodic Alumina. Appl. Phys. Lett. 71 (19), 2770-2772. doi:10.1063/1.120128

Miller, M. M., and Lazarides, A. A. (2005). Sensitivity of Metal Nanoparticle Surface Plasmon Resonance to the Dielectric Environment. J. Phys. Chem. B 109 (46), 21556-21565. doi:10.1021/jp054227y

Nguyen, N. T., Hwang, I., Kondo, T., Yanagishita, T., Masuda, H., and Schmuki, P. (2017). Optimizing TiO 2 Nanotube Morphology for Enhanced Photocatalytic H 2 Evolution Using Single-Walled and Highly Ordered TiO 2 Nanotubes Decorated with Dewetted Au Nanoparticles. Electrochemistry Commun. 79, 46-50. doi:10.1016/j.elecom.2017.04.016

O'sullivan, J. P., and Wood, G. C. (1970). The Morphology and Mechanism of Formation of Porous Anodic Films on Aluminium. Proc. R. Soc. Lond. A. Math. Phys. Sci. 317 (1531), 511-543. doi:10.1098/rspa.1970.0129

Oh, B.-R., Chen, P., Nidetz, R., McHugh, W., Fu, J., Shanley, T. P., et al. (2016). Multiplexed Nanoplasmonic Temporal Profiling of T-Cell Response under Immunomodulatory Agent Exposure. ACS Sens. 1 (7), 941-948. doi:10.1021/ acssensors.6b00240

Pan, S., and Rothberg, L. J. (2003). Interferometric Sensing of Biomolecular Binding Using Nanoporous Aluminum Oxide Templates. Nano Lett. 3 (6), 811-814.

Petryayeva, E., and Krull, U. J. (2011). Localized Surface Plasmon Resonance: Nanostructures, Bioassays and Biosensing-A Review. Analytica Chim. Acta 706 (1), 8-24. doi:10.1016/j.aca.2011.08.020

Pla, L., Santiago-Felipe, S., Tormo-Mas, M. Á., Pemán, J., Sancenón, F., Aznar, E., et al. (2020). Aptamer-capped Nanoporous Anodic Alumina for Staphylococcus aureus Detection. Sensors Actuators B: Chem. 320, 128281. doi:10.1016/j.snb. 2020.128281

Poinern, G. E. J., Ali, N., and Fawcett, D. (2011). Progress in Nano-Engineered Anodic Aluminum Oxide Membrane Development. Materials 4 (3), 487-526. doi:10.3390/ma4030487

Prabakar, S., Shiohara, A., Hanada, S., Fujioka, K., Yamamoto, K., and Tilley, R. D. (2010). Size Controlled Synthesis of Germanium Nanocrystals by Hydride Reducing Agents and Their Biological Applications. Chem. Mater. 22 (2), 482-486. doi:10.1021/cm9030599

Rajeev, G., Xifre-Perez, E., Prieto Simon, B., Cowin, A. J., Marsal, L. F., and Voelcker, N. H. (2018). A Label-free Optical Biosensor Based on Nanoporous Anodic Alumina for Tumour Necrosis Factor-Alpha Detection in Chronic Wounds. Sensors Actuators B: Chem. 257, 116-123. doi:10.1016/j.snb.2017. 10.156

Rath, A., and Theato, P. (2020). Advanced Aao Templating of Nanostructured Stimuli-responsive Polymers: Hype or Hope?. Adv. Funct. Mater. 30, 1902959. doi:10.1002/adfm.201902959

Ribes, À., Xifré-Pérez, E., Aznar, E., Sancenón, F., Pardo, T., Marsal, L. F., et al. (2016). Molecular Gated Nanoporous Anodic Alumina for the Detection of Cocaine. Scientific Rep. 6 (1), 1-9. doi:10.1038/srep38649

Rindzevicius, T., Alaverdyan, Y., Dahlin, A., Höök, F., Sutherland, D. S., and Käll, M. (2005). Plasmonic Sensing Characteristics of Single Nanometric Holes. Nano Lett. 5 (11), 2335-2339. doi:10.1021/nl0516355

Ringe, E., Sharma, B., Henry, A.-I., Marks, L. D., and Van Duyne, R. P. (2013). Single Nanoparticle Plasmonics. Phys. Chem. Chem. Phys. 15 (12), 4110-4129. doi:10.1039/c3cp44574g

Rodriguez, A., Molinero, D., Valera, E., Trifonov, T., Marsal, L. F., Pallarès, J., et al. (2005). Fabrication of Silicon Oxide Microneedles from Macroporous Silicon. Sensors Actuators B: Chem. 109 (1), 135-140. doi:10.1016/j.snb.2005. 03.015
Ruminski, A. M., King, B. H., Salonen, J., Snyder, J. L., and Sailor, M. J. (2010). Porous Silicon-Based Optical Microsensors for Volatile Organic Analytes: Effect of Surface Chemistry on Stability and Specificity. Adv. Funct. Mater. 20 (17), 2874-2883. doi:10.1002/adfm.201000575

Saito, M., Kitamura, A., Murahashi, M., Yamanaka, K., Hoa, L. Q., Yamaguchi, Y., et al. (2012). Novel Gold-Capped Nanopillars Imprinted on a Polymer Film for Highly Sensitive Plasmonic Biosensing. Anal. Chem. 84 (13), 5494-5500. doi:10.1021/ac300307e

Santos, A., Formentín, P., Pallarès, J., Ferré-Borrull, J., and Marsal, L. F. (2011). Structural Engineering of Nanoporous Anodic Alumina Funnels with High Aspect Ratio. J. electroanalytical Chem. 655 (1), 73-78. doi:10.1016/j.jelechem. 2011.02.005

Santos, A., Kumeria, T., and Losic, D. (2013a). Nanoporous Anodic Aluminum Oxide for Chemical Sensing and Biosensors. Trac Trends Anal. Chem. 44, 25-38. doi:10.1016/j.trac.2012.11.007

Santos, A., Kumeria, T., and Losic, D. (2013b). Optically Optimized Photoluminescent and Interferometric Biosensors Based on Nanoporous Anodic Alumina: a Comparison. Anal. Chem. 85 (16), 7904-7911. doi:10. $1021 / \mathrm{ac} 401609 \mathrm{c}$

Scully, J. C. (1983). Corrosion: Aqueous Processes and Passive Films. Academic Pr. Setoh, S., and Miyata, A. (1932). Researches on Anodic Film of Aluminium II, Anodic Behaviours of Aluminium in Aq. Solutions of Oxalic Acid. Sci. Pap. Inst. Phys. Chem. Res. Tokyo 19 (397), 237.

Shen, Y., Jia, R.-P., Luo, H.-Q., Chen, X.-G., Xue, D.-S., and Hu, Z.-D. (2004). Enhanced Photoluminescence of Morin-Bovine Serum Albumin on Porous Anodized Aluminum Oxide. Spectrochimica Acta A: Mol. Biomol. Spectrosc. 60 (5), 1007-1011. doi:10.1016/s1386-1425(03)00332-9

Sieber, I., Hildebrand, H., Friedrich, A., and Schmuki, P. (2005). Formation of SelfOrganized Niobium Porous Oxide on Niobium. Electrochemistry Commun. 7 (1), 97-100. doi:10.1016/j.elecom.2004.11.012

Sieber, I., Hildebrand, H., Friedrich, A., and Schmuki, P. (2006). Initiation of Tantalum Oxide Pores Grown on Tantalum by Potentiodynamic Anodic Oxidation. J. Electroceram 16 (1), 35-39. doi:10.1007/s10832-006-4351-7

Smith, A. (1974). U.S. Patent No. 3,850,762. Washington, DC: U.S. Patent and Trademark Office.

Song, C., Che, X., and Que, L. (2017). Nanopore Thin Film Enabled Optical Platform for Drug Loading and Release. Opt. Express 25 (16), 19391-19397. doi:10.1364/oe.25.019391

Stróż, A., Goryczka, T., and Łosiewicz, B. (2019). Electrochemical Formation of Self-Organized Nanotubular Oxide Layers on Niobium. Curr. Nanoscience 15 (1), 42-48. doi:10.1149/1.2781142

Su, X., Xu, Y., Zhao, H., Li, S., and Chen, L. (2019). Design and Preparation of Centrifugal Microfluidic Chip Integrated with SERS Detection for Rapid Diagnostics. Talanta 194, 903-909. doi:10.1016/j.talanta.2018.11.014

$\mathrm{Su}, \mathrm{Z}$., Zhou, W., Jiang, F., and Hong, M. (2012). Anodic Formation of Nanoporous and Nanotubular Metal Oxides. J. Mater. Chem. 22 (2), 535-544. doi:10.1039/ cljm13338a

Takmakov, P., Vlassiouk, I., and Smirnov, S. (2006). Application of Anodized Aluminum in Fluorescence Detection of Biological Species. Anal. Bioanal. Chem. 385 (5), 954-958. doi:10.1007/s00216-006-0504-4

Thompson, G. E., Furneaux, R. C., Wood, G. C., Richardson, J. A., and Goode, J. S. (1978). Nucleation and Growth of Porous Anodic Films on Aluminium. Nature 272 (5652), 433-435. doi:10.1038/272433a0

Ting, Y.-H., Liu, C.-C., Park, S.-M., Jiang, H., Nealey, P. F., and Wendt, A. E. (2010). Surface Roughening of Polystyrene and Poly(methyl Methacrylate) in Ar/O2 Plasma Etching. Polymers 2 (4), 649-663. doi:10.3390/polym2040649

Tinsley-Bown, A. M., Canham, L. T., Hollings, M., Anderson, M. H., Reeves, C. L., Cox, T. I., .., and Wun, A. (2000). Tuning the Pore Size and Surface Chemistry of Porous Silicon for Immunoassays. Physica status solidi (a) 182 (1), 547-553. doi:10.1002/1521-396X(200011)182:1<547::AID-PSSA547>3.0.CO;2-C

Vesel, A., and Semenic, T. (2012). Etching Rates of Different Polymers in Oxygen Plasma. Mate-rials Tech. 46 (3), 227-231.

Vlassiouk, I., Krasnoslobodtsev, A., Smirnov, S., and Germann, M. (2004). "Direct" Detection and Separation of dna Using Nanoporous Alumina Filters. Langmuir 20 (23), 9913-9915. doi:10.1021/la047959a

Wang, G., Lee, J.-H., Yang, Y., Ruan, G., Kim, N. D., Ji, Y., et al. (2015). ThreeDimensional Networked Nanoporous Ta2O5-X Memory System for Ultrahigh Density Storage. Nano Lett. 15 (9), 6009-6014. doi:10.1021/acs.nanolett.5b02190 
Wang, Y. X., Pan, Z. Y., Ho, Y. K., Xu, Y., and Du, A. J. (2001). Nuclear Instruments and Methods in Physics Research Section B: Beam Interactions with Materials and Atoms. Nucl. Instr. Methods Phys. Res. B 180 (1-4), 251-256. doi:10.1016/ s0168-583x(01)00425-6

Wei, W., Macak, J. M., Shrestha, N. K., and Schmuki, P. (2009). Thick Self-Ordered Nanoporous $\mathrm{Ta}$ [sub 2] $\mathrm{O}$ [sub 5] Films with Long-Range Lateral Order. J. Electrochem. Soc. 156 (6), K104. doi:10.1149/1.3116243

Whitney, A. V., Elam, J. W., Zou, S., Zinovev, A. V., Stair, P. C., Schatz, G. C., et al. (2005). Localized Surface Plasmon Resonance Nanosensor: A High-Resolution Distance-Dependence Study Using Atomic Layer Deposition. J. Phys. Chem. B 109 (43), 20522-20528. doi:10.1021/jp0540656

Willets, K. A., and Van Duyne, R. P. (2007). Localized Surface Plasmon Resonance Spectroscopy and Sensing. Annu. Rev. Phys. Chem. 58, 267-297. doi:10.1146/ annurev.physchem.58.032806.104607

Xia, X. H., Ashruf, C. M. A., French, P. J., and Kelly, J. J. (2000). Galvanic Cell Formation in Silicon/metal Contacts: the Effect on Silicon Surface Morphology. Chem. Mater. 12 (6), 1671-1678. doi:10.1021/cm9912066

Xue, D.-J., Wang, J.-J., Wang, Y.-Q., Xin, S., Guo, Y.-G., and Wan, L.-J. (2011). Facile Synthesis of Germanium Nanocrystals and Their Application in Organic-Inorganic Hybrid Photodetectors. Adv. Mater. 23 (32), 3704-3707. doi:10.1002/adma.201101436

Yan, B., Sun, K., Chao, K., Alharbi, N. S., Li, J., and Huang, Q. (2018). Fabrication of a Novel Transparent SERS Substrate Comprised of Ag-Nanoparticle Arrays and its Application in Rapid Detection of Ractopamine on Meat. Food Anal. Methods 11 (8), 2329-2335. doi:10.1007/s12161-018-1216-Z

Yang, Z., Si, S., Dai, H., and Zhang, C. (2007). Piezoelectric Urea Biosensor Based on Immobilization of Urease Onto Nanoporous Alumina Membranes. Biosens. Bioelectron. 22 (12), 3283-3287.

Yang, W., Li, Z., Lu, Z., Yu, J., Huo, Y., Man, B., et al. (2019). Graphene-Ag NanoparticlesCicada Wings Hybrid System for Obvious SERS Performance and DNA Molecular Detection. Opt. Express 27 (3), 3000-3013. doi:10.1364/oe.27.003000

Yeom, S.-H., Han, M.-E., Kang, B.-H., Kim, K.-J., Yuan, H., Eum, N.-S., et al. (2013). Enhancement of the Sensitivity of LSPR-Based CRP Immunosensors by $\mathrm{Au}$ Nanoparticle Antibody Conjugation. Sensors Actuators B: Chem. 177, 376-383. doi:10.1016/j.snb.2012.10.099

Yeom, S.-H., Kim, O.-G., Kang, B.-H., Kim, K.-J., Yuan, H., Kwon, D.-H., et al. (2011). Highly Sensitive Nano-Porous Lattice Biosensor Based on Localized Surface Plasmon Resonance and Interference. Opt. Express 19 (23), 22882-22891. doi:10.1364/oe.19.022882

Yoshikawa, H., Murahashi, M., Saito, M., Jiang, S., Iga, M., and Tamiya, E. (2015). Parallelized Label-free Detection of Protein Interactions Using a Hyper-
Spectral Imaging System. Anal. Methods 7 (12), 5157-5161. doi:10.1039/ c5ay00738k

Young, L. (1961). Anodic Oxide Films. London; New York: Academic Press.

Yu, H., Zhu, S., Yang, X., Wang, X., Sun, H., and Huo, M. (2013). Synthesis of Coral-like Tantalum Oxide Films via Anodization in Mixed OrganicInorganic Electrolytes. PLOS ONE 8, e66447. doi:10.1371/journal.pone. 0066447

Zhang, C. Y., Lu, Y., Zhao, B., Hao, Y. W., and Liu, Y. Q. (2016). Facile Fabrication of Ag Dendrite- Integrated Anodic Aluminum Oxide Membrane as Effective Three-Dimensional SERS Substrate. Appl. Surf. Sci. 377, 167-173. doi:10.1016/j. apsusc.2016.03.132

Zhang, J., Qu, S., Zhang, L., Tang, A., and Wang, Z. (2011). Quantitative Surface Enhanced Raman Scattering Detection Based on the "Sandwich" Structure Substrate. Spectrochimica Acta Part A: Mol. Biomol. Spectrosc. 79 (3), 625-630. doi:10.1016/j.saa.2011.03.045

Zhang, L., Macdonald, D. D., Sikora, E., and Sikora, J. (1998). On the Kinetics of Growth of Anodic Oxide Films. J. Electrochem. Soc. 145 (3), 898. doi:10.1149/1. 1838364

Zhao, Y., Chu, B., Zhang, L., Zhao, F., Yan, J., Li, X., ..., and Lu, Y. (2018). Constructing Sensitive SERS Substrate with a Sandwich Structure Separated by Single Layer Graphene. Sensors Actuators B: Chem. 263, 634-642. doi:10.1016/j. snb.2018.02.037

Zheng, Q., Lee, H. J., Lee, J., Choi, W., Park, N. B., and Lee, C. (2014). Electrochromic Titania Nanotube Arrays for the Enhanced Photocatalytic Degradation of Phenol and Pharmaceutical Compounds. Chem. Eng. J. 249, 285-292. doi:10.1016/j.cej.2014.03.111

Zhou, C., Yu, Z., Yu, W., Liu, H., Zhang, H., and Guo, C. (2019). Split AptamerBased Detection of Adenosine Triphosphate Using Surface Enhanced Raman Spectroscopy and Two Kinds of Gold Nanoparticles. Microchimica Acta 186 (4), 251. doi:10.1007/s00604-019-3356-2

Conflict of Interest: The authors declare that the research was conducted in the absence of any commercial or financial relationships that could be construed as a potential conflict of interest.

Copyright (C) 2021 Feng and Ji. This is an open-access article distributed under the terms of the Creative Commons Attribution License (CC BY). The use, distribution or reproduction in other forums is permitted, provided the original author $(s)$ and the copyright owner(s) are credited and that the original publication in this journal is cited, in accordance with accepted academic practice. No use, distribution or reproduction is permitted which does not comply with these terms. 